\title{
Time-lapse microgravity surveys reveal water storage heterogeneity of a karst aquifer
}

\author{
Thomas Jacob, ${ }^{1,2}$ Roger Bayer, ${ }^{1}$ Jean Chery, ${ }^{1}$ and Nicolas Le Moigne ${ }^{1}$ \\ Received 14 May 2009; revised 21 November 2009; accepted 13 January 2010; published 5 June 2010.
}

[1] Time-lapse microgravity surveying combined with absolute gravity measurements is used to investigate water storage changes in a karst aquifer of $\sim 100 \mathrm{~km}^{2}$ area. The survey consists of 40 gravity stations measured with a relative gravimeter; absolute gravity is measured at three stations for each survey. In total, four gravity surveys are performed over a 2 year time period during consecutive wet and dry periods. Survey precisions range between 2.4 and $5 \mu \mathrm{Gal}$, enabling statistically significant detection of $10 \mu \mathrm{Gal}$ change, i.e., $\sim 0.25 \mathrm{~m}$ equivalent water level change. Observed gravity changes are coherent between consecutive survey periods, i.e., net water withdrawal and net water recharge is observed, reaching changes as high as $22 \mu \mathrm{Gal}$. Observed gravity changes allow refining evapotranspiration estimates, which may serve to improve the water budget of the aquifer. High-and low-gravity amplitude zones characterize the karst system, demonstrating spatially variable storage behavior. Geomorphologic considerations are invoked to explain the location of preferential zones of water storage, and a conceptual model of water storage is discussed for the studied karst.

Citation: Jacob, T., R. Bayer, J. Chery, and N. Le Moigne (2010), Time-lapse microgravity surveys reveal water storage heterogeneity of a karst aquifer, J. Geophys. Res., 115, B06402, doi:10.1029/2009JB006616.

\section{Introduction}

[2] Ground-based field gravity measurements fall into two categories: absolute and relative measurements. Absolute gravimeters measure the value of $g$ using SI standards of length and time, hence yielding a gravity value qualified as "absolute," devoid of instrumental drift. The most precise commercially available absolute gravimeter is the FG-5 gravimeter manufactured by Microg-Lacoste (precision $\sim 1-$ $2 \mu \mathrm{Gal}, 1 \mu \mathrm{Gal}=10^{8} \mathrm{~m} \mathrm{~s}^{-2}$ ) [Niebauer et al., 1995]. This instrument is however not designed for intensive fieldwork, and large areas with numerous measurement sites cannot be monitored time efficiently. A field absolute gravimeter called A10 exists, yet its accuracy falls short of that of the FG5, with an accuracy of typically 5-10 $\mu$ Gal [Ferguson et al., 2008; Liard and Gagnon, 2002]. Relative field gravimeters (Lacoste and Romberg model D and Scintrex CG3 and CG5) can only measure gravity differences between stations. In particular, using these instruments in a network configuration allows for the determination of gravity differences over a wide region relative to a base station, with an accuracy of $\sim 5-10 \mu \mathrm{Gal}$ [Jousset et al., 1995]. These aforementioned instruments may be used for two types of applications: (1) measurement of the static gravity field,

\footnotetext{
${ }^{1}$ Géosciences Montpellier, UMR 5243, CNRS, Université Montpellier II, Montpellier, France.

${ }^{2}$ Now at Cooperative Institute for Research in Environmental Sciences and Department of Physics, University of Colorado at Boulder, Boulder, Colorado, USA.

Copyright 2010 by the American Geophysical Union. 0148-0227/10/2009JB006616
}

needed for gravity anomalies mapping and calculation of the geoid, and (2) measurement of the time variable gravity field, by effecting time-lapse or continuous measurements. The Earth's gravity field is not static: the best example is the tidal gravity changes in the diurnal and semidiurnal frequency bands (among others). Over longer time periods, gravity has been used to monitor postglacial rebound [Lambert et al., 2001; Larson and Van Dam, 2000], volcano and magma chamber processes [Ballu et al., 2003; Bonvalot et al., 2008; Budetta and Carbone, 1997; Furuya et al., 2003; Jousset et al., 2000; Rebscher et al., 2000], and tectonic deformation [Ergintav et al., 2007; Francis et al., 2004]. However, the largest source of noise in these studies has been identified as hydrology-related gravity effects [Bower and Courtier, 1998; Lambert and Beaumont, 1977; Mäkinen and Tattari, 1988]. Indeed, hydrology-related signal has a large frequency spectrum from rainfall events ( $\sim$ min [Meurers et al., 2007]) to long-term water table fluctuations ( $>1$ year) and are associated with significant gravity effects (one to several tens of microgals). Over the last decade, what was considered noise in the past is now the object of dedicated studies. For instance, the continuous and highly resolved gravity observations collected from GWR superconducting gravimeters [Goodkind, 1999] have been analyzed in term of local and regional hydrology-induced gravity effects [e.g., Abe et al., 2006; Boy and Hinderer, 2006; Crossley et al., 2005; Harnisch and Harnisch, 2006; Imanishi et al., 2006; Kroner and Jahr, 2006; Van Camp et al., 2006b]. However, superconducting gravimeters have not specifically been set up for hydrological studies but rather for studying geodynamics and Earth's structure [Hinderer and Crossley, 2000]. 
[3] Space-borne gravimetry with the GRACE mission has allowed unprecedented quantification of the time variable gravity field related to hydrology at the continental scale, with an accuracy of $1.5 \mathrm{~cm}$ of equivalent water height when smoothed over $1000 \mathrm{~km}$ [Wahr et al., 2004]. Because local catchment-scale studies cannot be addressed with spaceborne data, ground-based instruments intervene. Water storage change in the surroundings of a gravimeter influences gravity mainly through Newtonian attraction. As a rule of thumb, an infinite slab of $1 \mathrm{~m}$ of water represents an attraction of $\sim 42 \mu \mathrm{Gal}$.

[4] Time-lapse microgravity surveys dedicated to hydrological studies are few. Gravity changes have been compared to well water level changes in unconfined aquifers to obtain aquifer specific yield values [Gehman et al., 2009; Pool and Eychaner, 1995; Pool, 2008; Schmerge, 2003]. Naujoks et al. [2008] have measured minute $(<2 \mu \mathrm{Gal})$ gravity changes related to water storage changes. Such high survey precision was obtained on a small-scale network $(<10$ stations over distances $<1 \mathrm{~km})$ with a high number of gravimeters $(>3)$ so as to "stack" the measured gravity differences. Applying a similar measurement protocol to a larger network would be very time consuming. It must be noted that in the aforementioned studies, only relative gravity measurements are involved. With no absolute reference in a given survey, comparing consecutive survey results is done in the following manner. Either a site is considered to have a constant gravity value (usually sites with an expected low rock porosity), or gravity differences between given stations are examined between consecutive surveys, but the gravity change may be biased.

[5] In this study, time-lapse microgravity surveys are coupled with absolute gravity (AG) measurements on a karst system.

[6] Because of the structural heterogeneity of karst systems in which microscale to macroscale voids, fissures, and vast conduits coexist, water storage and flow cannot easily be described using a diffusion model. For this reason, classical hydrological methods such as well tests are illsuited to investigate lateral storage properties and their depth variation in karst system. Karst aquifers are classically analyzed with spring discharge hydrographs. This analysis yields integrative storage properties for the system as a whole. Because of the lack of water flow mapping inside the aquifer, the location and amplitude of water storage changes in a karst system are obscure. Only global aquifer properties are usually derived using this method [Baedke and Krothe, 2001; Dewandel et al., 2003; Kovacs et al., 2005].

[7] Van Camp et al. [2006a] have examined absolute gravity variations on a karst system during specific flood events. Recently, repeated absolute gravity measurements at three sites on the studied karst aquifer have revealed significant water storage changes at seasonal and inter annual timescales [Jacob et al., 2008]. Furthermore, repeated surface to depth gravity measurements have shown that water storage changes may occur within the top $60 \mathrm{~m}$ of the karst, plausibly in the epikarst, the uppermost horizon of the karst [Jacob et al., 2009]. The main goal of this study is to monitor horizontal gravity changes related to water storage changes on a wide region of the studied karst using microgravity surveying. 40 stations are measured at four successive wet and dry periods. We first examine the pre- cision of the surveys, and we then analyze the time-lapse gravity changes with respect to the hydrological knowledge of the basin.

\section{Survey Setup}

\subsection{Site Description}

[8] The Durzon karst system is located in the Grands Causses area, southern French Massif Central. This aquifer is embedded in a $400 \mathrm{~m}$ thick formation of middle to upper Jurassic limestones and dolomites, deposited on top of a 200 $\mathrm{m}$ thick upper Liassic marl formation [Bruxelles, 2001a] (Figure 1). This latter formation acts as an impermeable barrier that defines the lower limit of the saturated zone of the karst system. Middle Jurassic formations are predominant on the recharge area, particularly a $200 \mathrm{~m}$ thick dolomite formation of Bathonian age that largely outcrops.

[9] On the Durzon karst aquifer, the main recharge comes from rainfall, which infiltrates at the surface of the spring catchment (750 $\mathrm{m}$ elevation on average), and the discharge occurs at the Durzon Spring (533 m elevation). Thanks to its monitoring by the Parc Naturel Régional des Grands Causses, this perennial spring is known to have a mean daily discharge of $1.4 \mathrm{~m}^{3} \mathrm{~s}^{-1}$ (calculated over the 2002-2008 period) with a maximum daily discharge reaching $18 \mathrm{~m}^{3} \mathrm{~s}^{-1}$ during high-flow events.

[10] During exceptionally long rainfall periods, temporary lakes (shown in blue in Figure 1) appear at the south of the recharge area [Bruxelles, 2001a; Plagnes, 1997], their last appearance being in 1996. The return period of such events is $\sim 30$ years. These lakes may suggest that a large amount of precipitation may sometimes exceed the infiltration capacity of the epikarst and infiltration zone toward the saturated zone [Bruxelles, 2001a; Plagnes, 1997; Ricard and Bakalowicz, 1996]. The vadose zone, including the epikarst and infiltration zone is believed to have a different behavior in the north and south of the recharge area. It is well drained in the north, and inefficiently drained in the south [Bruxelles, 2001b; Ricard and Bakalowicz, 1996].

[11] In agreement with an accepted karst model [Mangin, 1975] the karst system may be horizontally layered into three zones.

[12] 1. The epikarst zone including both soil and weathered rock has 5-30 $\mathrm{m}$ depth. This zone has a high secondary porosity generated by dissolution and fractures and is expected to be an important water reservoir [Williams, 1983, 2008]. Indeed, surface to depth gravity measurements in a cave at BEAU site compared with absolute observations at BLAQ site (Figure 1) demonstrated predominant epikarst storage for this area of the karst system [Jacob et al., 2009].

[13] 2. The infiltration zone below is mostly composed of massive rock with pervasive open fissures and conduits, therefore insuring a fast vertical water transfer.

[14] 3. The saturated or phreatic zone, formed by large conduits, accommodates a mostly horizontal water flow to the outlet.

[15] As a result of the karst structure, spring hydrographs are primarily characterized by high-flow events consecutive to important precipitations and a long-term base flow component (Figure 2c). High-flow events result from fast water infiltration to the phreatic zone through enlarged drainage shafts and are generally short-lived. Base flow 


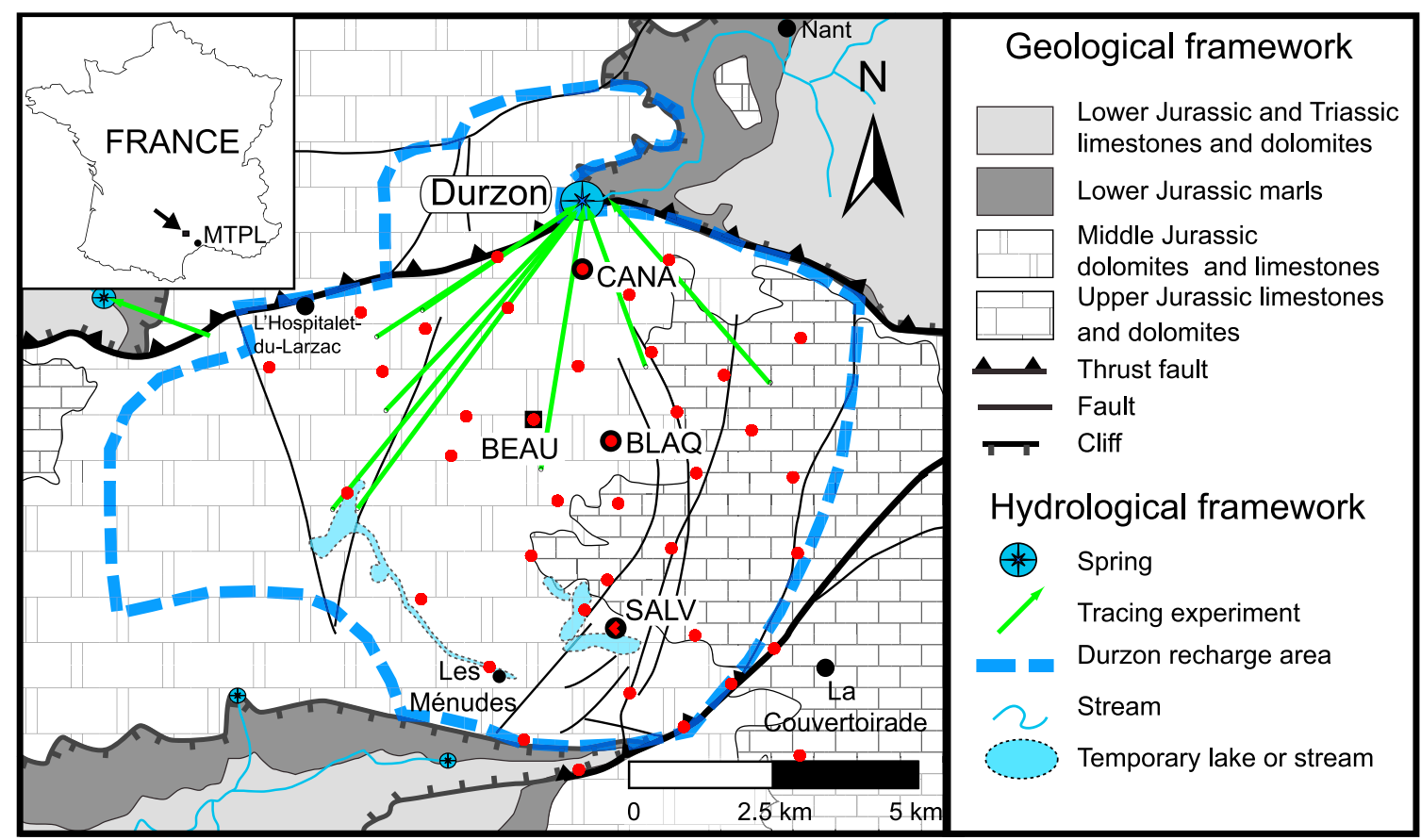

Figure 1. Geology and hydrology of the Durzon karst system, modified after Jacob et al. [2008]. Red dots represent the survey sites. Absolute gravity sites are BLAQ, SALV, and CANA. Site BEAU is the surface-to-depth gravity site [Jacob et al., 2009]. MTPL is the city of Montpellier.

discharge is sustained by groundwater storage within the karst. Although this water storage's location likely differs from karst to karst and lies within the epikarst and/or in the phreatic zone [Bakalowicz, 2005], its precise characterization remains elusive.

\subsection{Water Storage Variations Seen by Absolute Gravimetry}

[16] We monitor absolute gravity (AG) at sites SALV, BLAQ, and CANA (Figure 1) since January 2006 on a monthly basis with an FG5 absolute gravimeter (FG5 228, manufactured by Micro-g LaCoste). In order to obtain a gravity signal related exclusively to local hydrological changes, the regional or long-wavelength contribution of hydrology is removed. Regional hydrology-induced gravity changes are corrected for using the European Center for Medium-range Weather Forecasts (ECMWF, http://www. ecmwf.int) soil moisture model and snow model [Viterbo and Beljaars, 1995]. This "regional" effect is computed by convolving the surface mass distribution associated to soil moisture with the Green's functions associated to Newtonian and deformation effects, excluding a $0.25^{\circ} \times$ $0.25^{\circ}$ area around the study site [Boy and Hinderer, 2006]. As shown by Jacob et al. [2008], the amplitude of the corrected signal is $2 \mu \mathrm{Gal}$ at most. The residual gravity evolution at these three sites is shown in Figure 2a. Uncertainty on the $\mathrm{AG}$ values is close to $2 \mu \mathrm{Gal}$, representing the quadratic sum of the instrumental noise and the setup error [Niebauer et al., 1995; Van Camp et al., 2005].

[17] The general trend of the gravity variations can be explained by means of mass balance modeling. Taking into account input (rainfall, Figure 2b) and output (spring discharge, Figure 2c, and evapotranspiration) water at the scale of the karst recharge area, water storage changes are determined and converted into a karst system-scale gravimetric water stock (GWS) (see Jacob et al. [2008] for a detailed explanation). Gravity therefore increases consecutively to precipitations (see, e.g., September-October 2006, Figures $2 \mathrm{a}$ and $2 \mathrm{~b}$ ), while it decreases during dry periods due to evapotranspiration and spring discharge (see MaySeptember 2006, July-September 2007, June-September 2008). Furthermore, surface to depth gravity measurements have demonstrated that most water storage variations occur in the top $60 \mathrm{~m}$ of the karst, most probably in the epikarst horizon at BEAU site (Figure 1) [Jacob et al., 2009]. One way to interpret annual amplitudes ranging some tens of $\mu \mathrm{Gal}$ observed at the three AG sites (Figure 2a) is to invoke water storage changes in the superficial vadose area (i.e., soil, epikarst and a part of the infiltration zone). Deeper water storage changes in the phreatic zone may to some extent also account for observed gravity changes. The nonuniqueness of surface gravity measurements prevents the vertical determination of water storage changes.

[18] The main goal of this study is to extend the gravity monitoring from the three AG sites to the rest of the karst recharge area in order to detect possible lateral water storage properties. Microgravity surveying has been conducted in order to address this issue.

\subsection{Survey Measurement Protocol}

[19] As much as possible, microgravity surveys have been performed during periods of high gravity, corresponding to high water storage, and low gravity, corresponding to low water storage (see survey periods marked from S1 to S4 in Figure 2a). In this way, significant spatial information on water storage change can be captured for discharge (gravity 


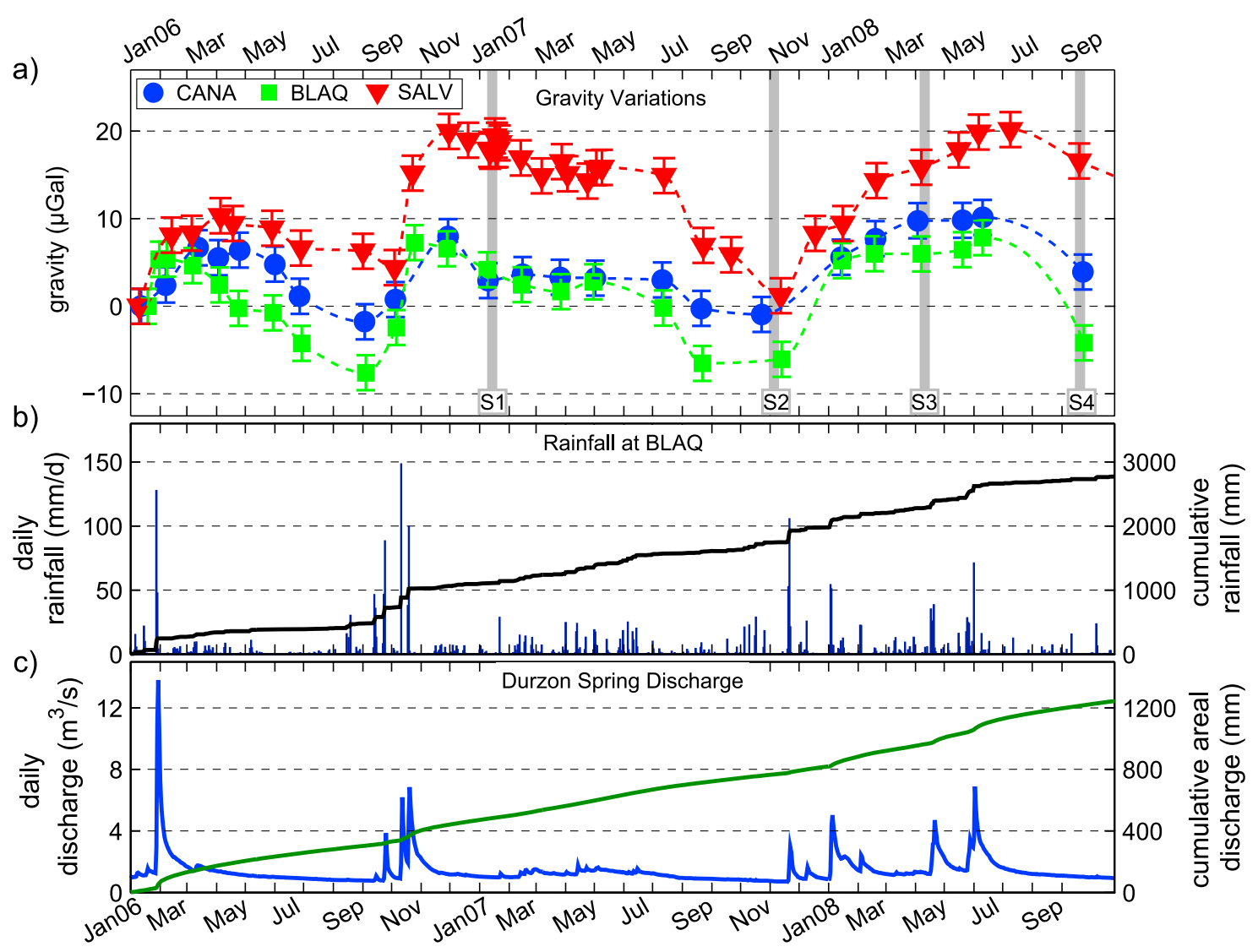

Figure 2. (a) Absolute gravity variations at site CANA, BLAQ, and SALV, corrected for regional hydrology (see text for explanations). Survey periods S1 to S4 are indicated by vertical gray bars. (b) Daily and cumulative rainfall measured at BLAQ. (c) Daily Durzon spring discharge (blue line) and cumulative areal discharge (green line).

high to gravity low) and recharge (gravity low to gravity high) conditions.

[20] Gravity surveys consist of 40 stations or measurement sites that include the three AG sites (see Figure 1). The largest gravity difference in the survey is $\sim 28.4 \mathrm{mGal}$. The three AG sites are measured immediately before or after the gravity survey, so that absolute gravity values at these three sites are known (Figure 2a). Because no significant rainfall events occur during the survey periods, we consider the absolute gravity values to be stable during the survey periods. The surveys are performed with one Scintrex CG-5 Autograv relative gravimeter (CG5 030200167). Scintrex relative gravimeters have been used in the past for precise microgravimetry surveys [Ballu et al., 2003; Bonvalot et al., 2008; Jousset et al., 2000; Merlet et al., 2008]. The CG-5 instrument has a reading resolution of $1 \mu \mathrm{Gal}$ and a repeatability of less than $10 \mu \mathrm{Gal}$ [Scintrex Limited, 2006]. Its gravity sensor is based on a capacitive displacement transducer electrostatic feedback system to detect movements of the fused quartz proof mass and to force the mass back to a null position. The drift of the CG-5 sensor is caused by an unavoidable creep of the quartz spring, whose length under tension increases. An important feature of this sensor is that its drift can be considered linear within a few hours when the instrument is transported with care [Scintrex Limited, 2006]. The gravity survey consists of 12 loops that start and end at SALV AG site to evaluate the temporal drift. CANA and
BLAQ AG sites are often reoccupied within loops to further improve the determination of the drift. Within each loop, 5 to 10 gravity stations are measured. A gravity tie is defined as the gravity difference between two consecutive gravity stations within a loop. The number of gravity ties was initially 101 for the first survey and reached 114 ties for survey 3 and 4 (Table 1), as the survey measurement protocol was optimized. Station spacing is typically $1.5 \mathrm{~km}$ (Figure 1), and each station is set up on hard rock (limestone or dolomite). Stations are materialized by a monument installed in the rock (a bolt), where the CG5 tripod is rigorously always installed in the same manner for every survey. CG5 tripod height (and therefore CG5 gravity sensor height) is kept constant at every station by the use of a brass ring that maintains one tripod foot at fixed height (see Figure 4). In this manner, the CG5 gravity sensor is at a fixed position at measurement stations for all surveys, and therefore no height corrections need to be applied, hence removing associated uncertainties.

Table 1. Survey Information

\begin{tabular}{lcccc}
\hline & $\begin{array}{c}\text { Measurement } \\
\text { Period }\end{array}$ & $\begin{array}{c}\text { Number of } \\
\text { Stations }\end{array}$ & $\begin{array}{c}\text { Number of } \\
\text { Loops }\end{array}$ & $\begin{array}{c}\text { Number of } \\
\text { Gravity Ties }\end{array}$ \\
\hline Survey 1 & 17-25 Jan 2007 & 40 & 12 & 101 \\
Survey 2 & 29 Oct to 8 Nov 2007 & 40 & 12 & 111 \\
Survey 3 & 3-10 Apr 2008 & 40 & 12 & 114 \\
Survey 4 & 16-23 Sep 2008 & 40 & 12 & 114 \\
\hline
\end{tabular}




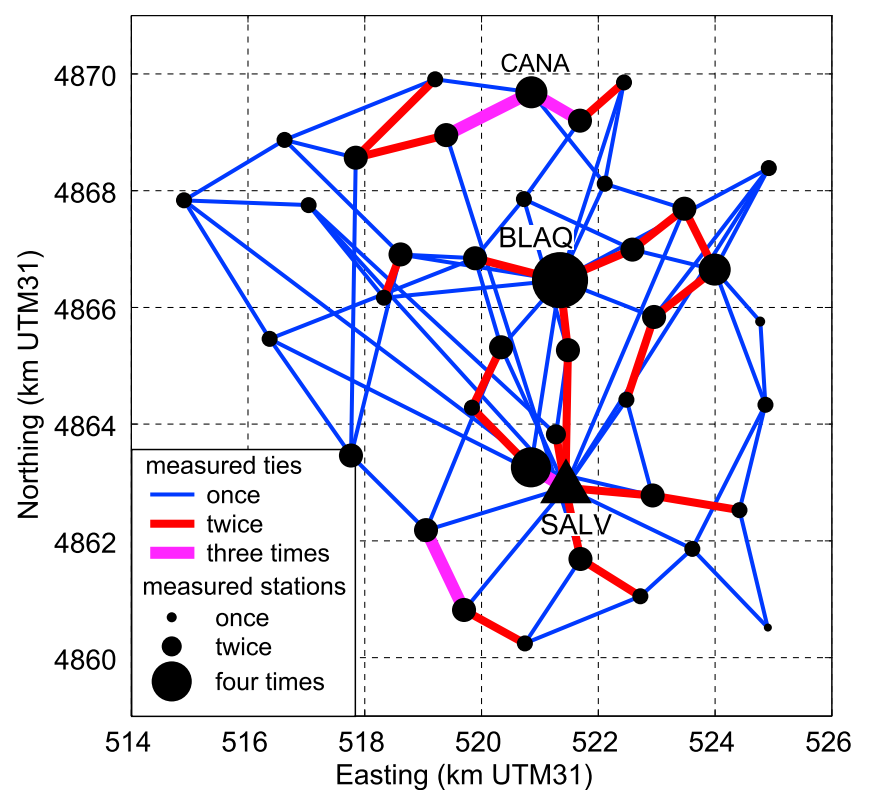

Figure 3. Survey map of gravity ties showing the frequency of the measured ties and the number of reoccupations of each station. SALV base station is represented as a triangle.

We assume that station elevations do not evolve with respect to one another between consecutive surveys on the basis of the fact that the survey is set up on low-compressibility limestone and dolomite. This assumption may not hold true in other environments, such as alluvial aquifers or permafrost terrain, where precise geodetic leveling of station elevations needs to be performed during each survey [Ferguson et al., 2007; Pool, 2008].
[21] At each station, the CG5 is set up to record five $90 \mathrm{~s}$ gravity measurements at $6 \mathrm{~Hz}$ sampling rate. To minimize environmental effects on measurement precision, a portable shelter was used to shield the gravimeter. Such effects include wind vibrations and heat-induced tripod tilt from the sun.

[22] These gravity surveys typically necessitate 6 days of field work (see Table 1). We designed the surveys so that almost every station be measured at least twice within independent loops. Only two stations failed to meet that requirement and were occupied once during each survey (see Figure 3). This measurement protocol yields precise adjusted gravity values in the least squares inversion.

\section{Data Processing}

\subsection{Corrections}

[23] The gravity measurements are first corrected for Earth tides using ETGTAB software [Wenzel, 1996] with the Tamura tidal potential development [Tamura, 1987], ocean loading effects with FES2004 ocean tide model [Lyard et al., 2006] and atmospheric pressure loading using an admittance value of $-0.3 \mu \mathrm{Gal} \mathrm{hPa}^{-1}$. Atmospheric pressure is measured at SALV station (see Figure 1) at a $15 \mathrm{~min}$ rate with a $0.1 \mathrm{hPa}$ precision. AG values are corrected for polar motion effects, but not relative gravity values as the polar motion correction does not significantly vary within survey time span ( $\sim$ week).

\subsection{Linking Absolute Gravity Values to Relative Values}

[24] Absolute gravity values measured by the FG5 gravimeter need to be transferred to the CG5 gravity sensor height. The absolute gravity value is determined from the adjustment of the trajectory of a free-falling corner cube (see Figure 4) to the equation of motion [Niebauer et al., 1995]. The resulting gravity value $g_{0}$ is defined at a height

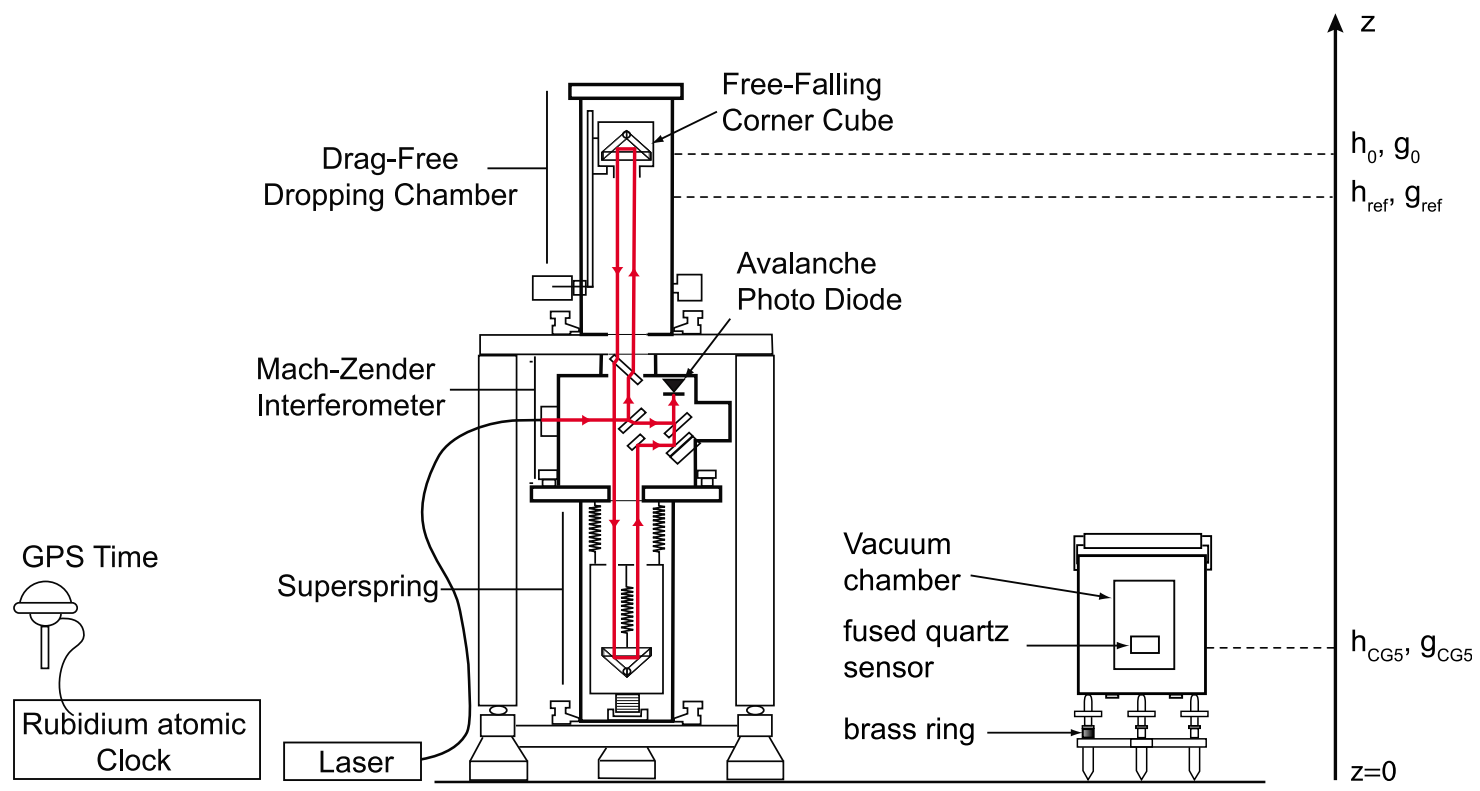

Figure 4. FG5 absolute gravimeter and CG5 relative gravimeter in operation (not to scale). Heights and associated gravity values are illustrated (see text for explanations). 
Table 2. Gravity Gradient and Gravity Values Transferred to CG5 Heights for the Three AG Stations for Each Survey ${ }^{a}$

\begin{tabular}{lccccc}
\hline & & \multicolumn{4}{c}{$g_{\text {CG5 }}$ Survey $(\mu \mathrm{Gal})$} \\
\cline { 3 - 6 } & \begin{tabular}{c} 
Gradient \\
\cline { 3 - 6 }
\end{tabular} & 1 & 2 & 3 & 4 \\
\hline SALV & 311.8 & 980339143 & 980339126 & 980339141 & 980339141 \\
BLAQ & 335.8 & 980335714 & 980335704 & 980335717 & 980335706 \\
CANA & 273.2 & 980356126 & 980356122 & 980356134 & 980356127 \\
\hline
\end{tabular}

${ }^{\mathrm{a}}$ Gravity values are corrected for regional hydrology.

corresponding to the top of the "drop" (typically $0.2 \mathrm{~m}$ long) of the free-falling object. The vertical gravity gradient at the measurement site is important to determine $g$ through the equation of motion [see Niebauer et al., 1995]. Furthermore, it is also used to transfer the gravity value $g_{0}$ to a userdefined height $h$. The vertical gravity gradient is determined by measuring gravity ties with a CG5 relative gravimeter between different heights; precision on the gravity gradient is typically 2 to $3 \mu \mathrm{Gal} \mathrm{m}$. The gradient was measured with a special tripod at heights $0,0.6$, and $1.2 \mathrm{~m}$ above ground. Results are shown in Table 2 for the three AG sites. Inaccuracies in the gradient estimate therefore bring further uncertainty to the gravity value $g_{0}$, but they mostly affect the uncertainty of all transferred gravity values. In order to minimize these uncertainties, the reference gravity value $g_{\text {ref }}$ independent of the gravity gradient at height $h_{\text {ref }}$ was determined. Several authors have worked on the determination of $h_{\text {ref }}$, which, as a rule of thumb, is located approximately one third of the way down the drop [Niebauer, 1989; Timmen, 2003; Zumberge, 1981]. Height $h_{\text {ref }}$ and associated gravity value $g_{\text {ref }}$ were determined by means of trial and error for each AG measurement during each survey. Height $h_{\text {ref }}$ depends on instrument dimensions and instrument setup. Because the same operator was used for every AG measurement, determined $h_{\text {ref }}$ range between 1.217 and $1.220 \mathrm{~m}$.

[25] The reference gravity value is then transferred to the CG5 sensor height $h_{\mathrm{CG} 5}$ using the following relationship:

$$
g_{\mathrm{CG} 5}=g_{\mathrm{ref}}+\operatorname{grad}(g)\left(h_{\mathrm{ref}}-h_{\mathrm{CG} 5}\right)
$$

CG5 sensor height $h_{\mathrm{CG} 5}$ takes into account tripod height and manufacturer's specifications [Scintrex Limited, 2006] and ranges between 0.261 and $0.271 \mathrm{~m}$ above ground depending on the brass ring used. Resulting gravity values corrected for regional hydrology are shown in Table 2.

[26] Taking into account the error on the measured gradient, $\sim 3 \mu \mathrm{Gal} \mathrm{m}{ }^{-1}$, and the uncertainty of the $\mathrm{AG}$ value, $\sim 2 \mu \mathrm{Gal}$, the error on $g_{\mathrm{CG} 5}$ (see equation (1)) is $\sim 4 \mu \mathrm{Gal}$, as determined from an uncertainty analysis. This latter uncertainty value is used in the least squares adjustment.

\subsection{Least Squares Adjustment}

[27] Once the gravity data are corrected for the above stated contributions and absolute gravity values are transferred to the relative gravimeter sensor height, gravity values and drifts for each loop are least squares adjusted. Software MCGRAVI [Beilin, 2006] based on the inversion scheme of GRAVNET [Hwang et al., 2002] is used. The principles of the adjustment are detailed in the following. Unknowns to be adjusted are gravity values at each station and the gravimeter drift for each loop. The instrumental drift is assumed to be linear due to the short time span of the loops $(<4 \mathrm{~h})$. Within loop number $k$, the measured gravity tie between stations $s_{j}$ and $s_{i}$ can be expressed as

$$
C_{f}\left(m_{s_{j}}^{t_{j}}-m_{s_{i}}^{t_{i}}\right)+v_{s_{i}}^{s_{j}}=g_{j}-g_{i}+D_{k}\left(t_{j}-t_{i}\right)
$$

where $C_{f}$ is the relative meter calibration correction factor, $m_{s_{j}}^{t_{j}}$ and $m_{s_{j}}^{t_{j}}$ are mean gravity readings at stations $s_{j}$ and $s_{i}$ at times $t_{j}$ and $t_{i}$, respectively, relative to the first measurement in the loop, $v_{s_{i}}^{s_{i}}$ the residual of $\left(m_{s_{j}}^{t_{j}}-m_{s_{i}}^{t_{i}}\right), g_{j}$ and $g_{i}$ the gravity values at stations $s_{j}$ and $s_{i}$ to be adjusted, and $D_{k}$ the drift within loop $k$.

[28] An absolute gravity measurement $g_{s_{i}}^{a b s}$ is linked to the gravity value $g_{i}$ to be adjusted by

$$
g_{s_{i}}^{a b s}+v_{s_{i}}^{a b s}=g_{i}
$$

The matrix representation of the observation equations for $n$ gravity stations and $m$ loops is

$$
\mathbf{L}+\mathbf{V}=\mathbf{A} \mathbf{X}
$$

where $\mathbf{L}$ is the $n$ vector of relative and absolute gravity readings and $\mathbf{V}$ is the $n$ vector of residuals, $\mathbf{A}$ is the $n \times(m+s)$ design matrix and $\mathbf{X}$ is the $m+s$ vector of unknowns to be inverted, i.e., $m$ gravity values (one for each station) and $s$ linear drifts (one for each loop). $\mathbf{L}$ has a $n \times n$ weight matrix $\mathbf{P}$ given by the inverse of the variance of the gravity readings: the standard deviation of a $90 \mathrm{~s}$ measurement series for the relative measurements. Because such standard deviations are almost exclusively dependent on microseismic noise, we quadratically add $5 \mu \mathrm{Gal}$ to each standard deviation from relative gravity readings to account for possible setup errors. Also included in the weight matrix are the errors on the transferred absolute gravity values, set to $4 \mu \mathrm{Gal}$ (see section 3.2).

[29] Solving for this linear weighted least squares problem yields $\mathbf{X}$

$$
\mathbf{X}=\left(\mathbf{A}^{\mathbf{T}} \mathbf{P A}\right)^{-\mathbf{1}}\left(\mathbf{A}^{\mathbf{T}} \mathbf{P L}\right)
$$

and the residuals are given by

$$
\mathbf{V}=\mathbf{A X}-\mathbf{L}
$$

The a posteriori variance of unit weight is computed as

$$
\sigma_{0}^{2}=\frac{V^{T} P V}{n-(m+s)}
$$

where $n-(m+s)$ is the degree of freedom of the least squares fit. The a posteriori covariance matrix of $\mathbf{X}$ is

$$
\sum=\sigma_{0}^{2}\left(\mathbf{A}^{\mathbf{T}} \mathbf{P A}\right)^{-1}
$$

In order to obtain the most accurate adjusted gravity values, the calibration correction factor $C_{f}$ must be precisely determined.

\subsection{Calibration}

[30] As demonstrated by Budetta and Carbone [1997], Scintrex relative gravimeters need to be regularly calibrated when used to detect small gravity variations over extended periods of time. The calibration correction factor with 


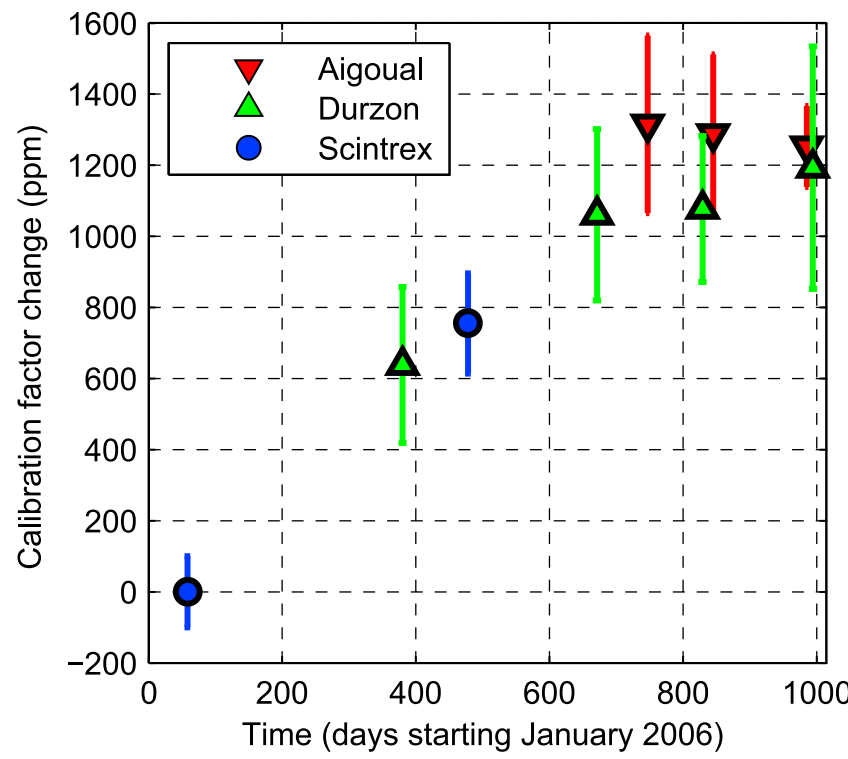

Figure 5. CG5 167 calibration factor change as a function of time. Modified after Jacob et al. [2009]. Aigoual is the Mount Aigoual gravity range, Durzon is the calibration from the present survey, and Scintrex is the factory gravity range in Canada.

respect to the instrument calibration constant is classically constrained by performing calibration line measurements where large known differences in gravity are compared to those measured by the relative gravimeter [Debeglia and Dupont, 2002; Flury et al., 2006]. In the case of a network adjustment where absolute gravity values in the network are known, the calibration correction factor $C_{f}$ may be determined by solving the nonlinear equations (4) by an iterative least squares adjustment. The calibration factor change for CG-5 167 is calculated from various calibration lines and for the four microgravity surveys as shown in Figure 5.

[31] The Scintrex calibration line is known as the Orangeville calibration line and is located in Ontario, Canada. It spans $119 \mathrm{mGal}$ between five stations over a $70 \mathrm{~km}$ distance [Scintrex Limited, 2006]. The accuracy on the calibration factor is $10^{-4}$. The Aigoual calibration line is composed of three stations between Montpellier and Mont Aigoual, south of France, spanning more than $300 \mathrm{mGal}$. The accuracy on the calibration is also $10^{-4}$. The evolution of the calibration factor is of 1 part in a thousand over a 2 year period.

\section{Results}

\subsection{Survey Accuracies and Error Budgets}

[32] Figure 6 shows the histograms of the gravity tie residuals and of the errors on adjusted gravity values, and Table 3 summarizes these histograms. For a given survey, gravity tie residuals may both reflect the time variation of water storage during this survey and instrumental errors such as tares. However, all surveys are performed during stable hydrological conditions (no heavy precipitation) and we therefore assume that tie residuals are only representative of instrumental error. The first three surveys have similar errors, and survey 4 is the least accurate. The standard deviations of the gravity tie residuals span between 2.9 and $5.8 \mu \mathrm{Gal}$ and the mean errors on adjusted gravity values are in the range of 2.4 to $5 \mu \mathrm{Gal}$ for the four surveys. Because the same measurement protocol, operators, and instruments were used for all surveys and because no measurements were performed during the aftermath of a strong remote earthquake which deteriorates instrument precision, differences in survey accuracies seem to be related to instrumental performance.

[33] This is particularly true for survey 4, whose tie residual histogram is very wide $(5.8 \mu \mathrm{Gal}$ standard deviation) compared to those of the other surveys (Figure 6). Indeed, the Scintrex CG5 exhibited internal temperature stabilization deficiencies during survey 4, which plausibly had a negative influence on measurement accuracy [Flury et al., 2006; Scintrex Limited, 2006]. The internal temperature exhibited abnormally large changes, up to $\sim 1 \mathrm{mK}$ during each site occupation. Thermal effects on the quartz sensor may not have been well corrected for. As a result, errors on adjusted gravity values are higher for this campaign than for the previous ones.

[34] The precision of gravity values obtained from each survey network adjustment conditions the precision of the time-lapse gravity differences between consecutive surveys. The error in the gravity value for each survey is assumed independent and therefore the error on the gravity change for a particular site is the quadratic sum of this site's errors for the considered surveys.

[35] Let $\Delta t_{1}^{2}, \Delta t_{2}^{3}$, and $\Delta t_{3}^{4}$ be the time periods between surveys 1 to 2,2 to 3 , and 3 to 4 , respectively. Let $\Delta g_{1}^{2}$, $\Delta g_{2}^{3}$, and $\Delta g_{3}^{4}$ be the gravity field differences for $\Delta t_{1}^{2}, \Delta t_{2}^{3}$, and $\Delta t_{3}^{4}$, respectively. It is usually assumed that statistically significant gravity changes are those whose amplitudes are twice larger than the gravity change error. Mean consecutive survey errors, shown in Table 3, are 4.6, 4 and 5.5 $\mu \mathrm{Gal}$ for $\Delta g_{1}^{2}, \Delta g_{2}^{3}$, and $\Delta g_{3}^{4}$, respectively. Hence, statistically significant gravity changes detected between these consecutive surveys cannot be lower than 9.2, 8 , and $11 \mu \mathrm{Gal}$, respectively, on average. As a consequence, statistically significant gravity changes occur at $67.5 \%, 82.5 \%$, and $60 \%$ of the sites for gravity differences $\Delta g_{1}^{2}, \Delta g_{2}^{3}$, and $\Delta g_{3}^{4}$, respectively (Figure 7). This percentage depends on both consecutive survey accuracies and on temporal gravity change amplitudes.

\subsection{Time-Lapse Gravity Changes}

[36] Gravity changes $\Delta g_{1}^{2}, \Delta g_{2}^{3}$, and $\Delta g_{3}^{4}$ are represented on Figure 7 (and are available as auxiliary material). ${ }^{1}$ The gravity differences are interpolated with a cubic interpolation and represented as contour maps. For $\Delta g_{1}^{2}$, gravity differences are in the range of -1.1 to $-21.9 \mu \mathrm{Gal}$ with an average value of $-12.2 \mu \mathrm{Gal} . \Delta g_{2}^{3}$ is characterized by gravity values between 4.2 and $23.4 \mu \mathrm{Gal}$, averaging $13.2 \mu \mathrm{Gal}$. Finally, gravity changes ranging between -1.7 and $-24.2 \mu \mathrm{Gal}$ are observed for $\Delta g_{3}^{4}$ (see Figure 7 ); the mean gravity change being of $-12.3 \mu \mathrm{Gal}$.

[37] The sign of the gravity changes between consecutive measurement periods is homogeneous for every station: $\Delta g_{1}^{2}$ and $\Delta g_{3}^{4}$ are characterized by net gravity decreases, while

\footnotetext{
${ }^{1}$ Auxiliary materials are available in the HTML. doi:10.1029/ 2009JB006616.
} 
a) Survey 1

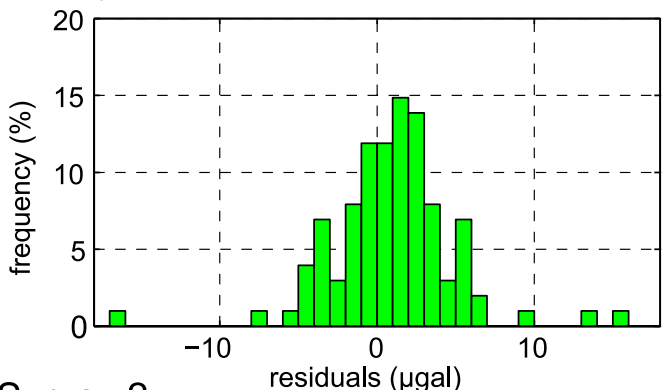

b) Survey 2

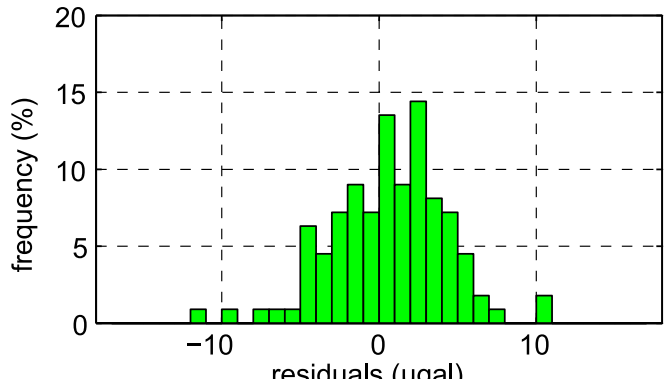

c) Survey 3

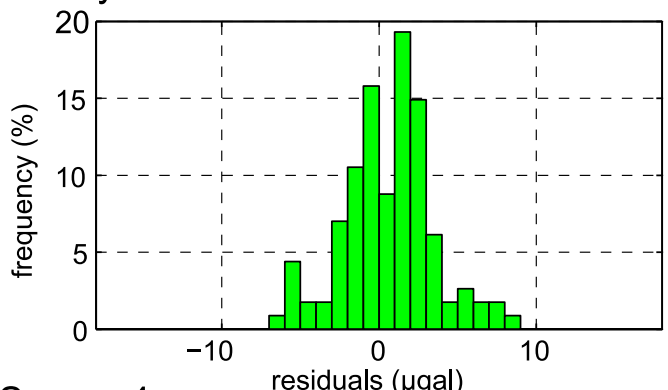

d) Survey 4

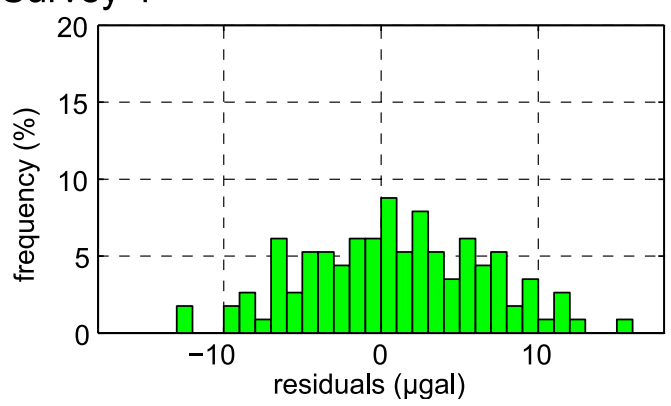

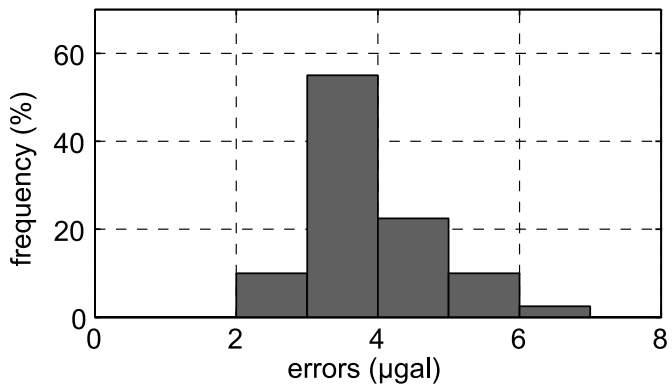
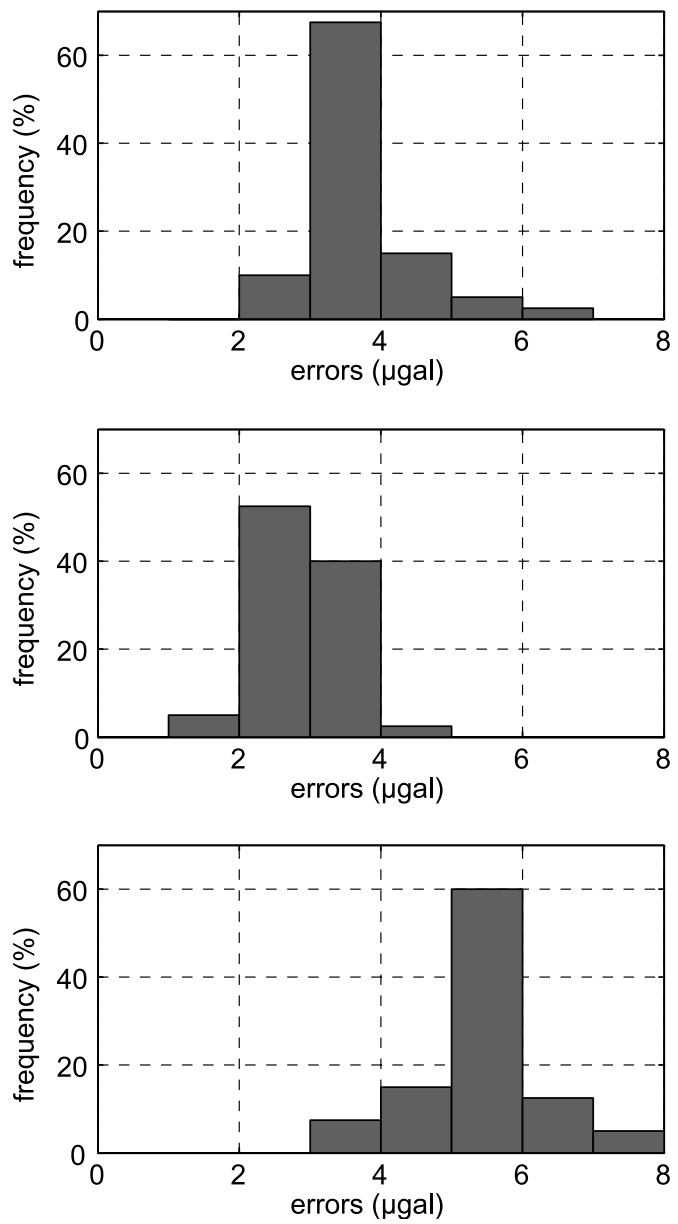

Figure 6. Gravity tie residuals and adjusted gravity errors histograms for the four surveys.

$\Delta g_{2}^{3}$ shows a net gravity increase. The spatial pattern of the gravity changes is different for each map, yet some similarities exist between the maps. For example, highamplitude changes systematically occur to the west of SALV station (Figure 7). As for AG gravity changes for SALV, CANA, and BLAQ sites, mapping the gravity changes reveals a large variability of water storage in this karst system.

\section{Interpretation and Discussion}

[38] Time-lapse microgravity surveying allows the quantification of water storage changes at the karst recharge area
Table 3. Standard Deviation of Gravity Tie Residuals and Mean Error on Adjusted Gravity for Measured Surveys ${ }^{\mathrm{a}}$

\begin{tabular}{lcccc}
\hline & $\begin{array}{c}\text { Gravity Tie } \\
\text { Residuals } \\
(\mu \mathrm{Gal})\end{array}$ & $\begin{array}{c}\text { Mean Error on } \\
\text { Adjusted Gravity } \\
(\mu \mathrm{Gal})\end{array}$ & $\begin{array}{c}\text { Consecutive } \\
\text { Survey Error } \\
(\mu \mathrm{Gal})\end{array}$ & $\begin{array}{c}\text { Mean Gravity } \\
\text { Change } \\
\overline{\Delta g}_{i-1}^{i}(\mu \mathrm{Gal})\end{array}$ \\
\hline Survey 1 & 4 & 3.3 & & \\
Survey 2 & 3.7 & 3.2 & 4.6 & -12.2 \\
Survey 3 & 2.9 & 2.4 & 4.0 & +13.2 \\
Survey 4 & 5.8 & 5.0 & 5.5 & -12.3 \\
\hline
\end{tabular}

${ }^{\mathrm{a}}$ Error between two consecutive surveys is shown. The mean gravity change between two consecutive surveys is shown. 

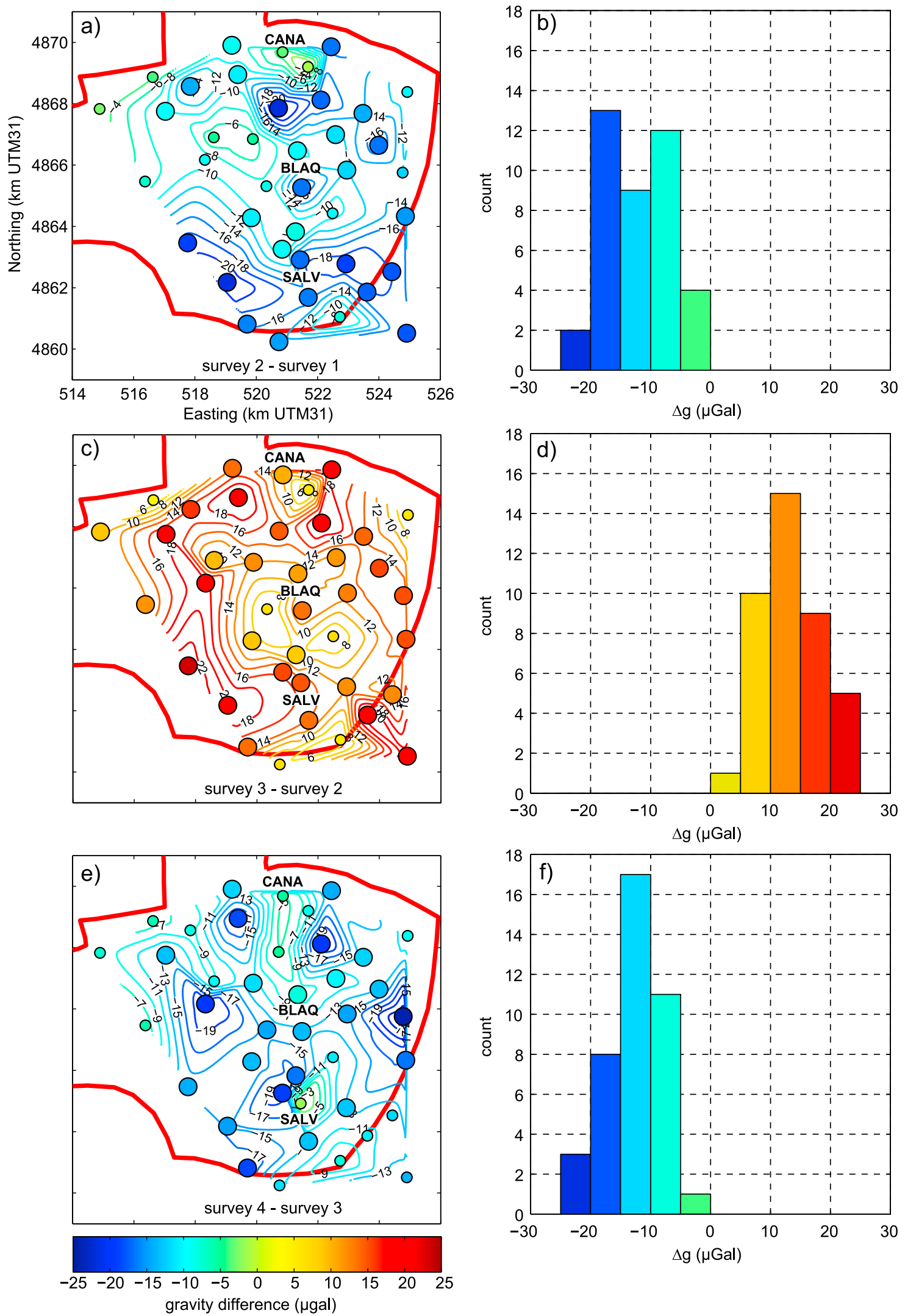

Figure 7. Gravity difference between consecutive surveys: (a) surveys 1 to 2 , (c) surveys 2 to 3 , and (e) surveys 3 to 4 . Color circles represent gravity differences at measurement sites according to the given color bar. Large and small circles are statistically significant and insignificant gravity differences, respectively. Contour map numbers are in $\mu \mathrm{Gal}$. (b, d, and $\mathrm{f}$ ) Associated histograms. 
a)

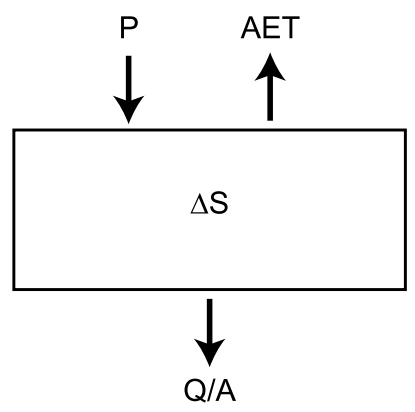

b)

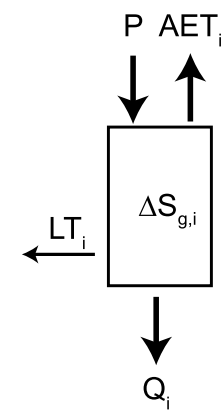

Figure 8. (a) Global water budget representation according to equation (13). (b) Local water budget representation according to equation (14).

scale. The discussion is organized as follows: first, mean gravity changes are used as constraints on the karst system water budget. Then, we attempt to interpret the variability of the gravity signal in terms of water transfer and storage at a local scale. Finally, geomorphologic considerations are invoked to explain observed spatial heterogeneity in water storage change. We conclude by inferring karst functioning from observed spatial heterogeneity.

\subsection{Gravity Observations as a Global Constraint on Water Storage}

[39] Observed gravity changes are now used to constrain the water budget on the karst system as a whole.

[40] Areal water storage changes $\Delta S$ at the karst system scale are driven by input and output water fluxes, namely, rainfall $\mathrm{P}$ as input, and actual evapotranspiration AET and spring discharge $\mathrm{Q}$ as outputs. The water budget per unit area for the karst system can be expressed as

$$
\Delta S=P^{c}-\mathrm{AET}^{c}-\frac{Q^{c}}{A}
$$

where $A$ is the karst recharge area and the superscript " $c$ " stands for cumulative values (Figure 8a).

[41] We use rain gauge data of the BLAQ station (Figure 1) as a proxy for average basin precipitation. Five rain gauges installed on the karst recharge area allow assessing that rainfall distribution across the basin is quite homogeneous. Spring discharge is monitored by the Parc Naturel Régional des Grands Causses (PNRGC) and is readily available. Karst recharge area $A$ is considered to be $\sim 100 \mathrm{~km}^{2}$ according to geological, geomorphological, and mass balance considerations [Bruxelles, 2001a; Ricard and Bakalowicz, 1996].

[42] Actual evapotranspiration (AET) is the amount of water transpired by the plants and evaporated from the soil that returns to the atmosphere. At the hydrological catchment scale, this quantity is difficult to assess due to the difficulty to monitor in situ air-soil water vapor exchange. A better known quantity is the potential evapotranspiration (PET), which is the amount of water that could be evaporated and transpired if water were not a limiting factor. PET can be calculated from meteorological quantities (solar radiation, wind speed, air humidity...) and represents the evaporative demand of the atmosphere. Contrary to actual evapotranspiration, potential evapotranspiration does not depend on soil and vegetation properties and therefore dis-

plays less variability. For the study area, PET has the shape of a 1 year period function with maxima during warm sunny summer months (PET $>5 \mathrm{~mm} \mathrm{~d}^{-1}$ ) and minima during cold winter months (PET $<1 \mathrm{~mm} \mathrm{~d}^{-1}$ ). We use PET values calculated with the Penman-Monteith method [Monteith, 1965; Penman, 1948] by Météo-France some $7 \mathrm{~km}$ to the south of the recharge area at Le Caylar station.

[43] Let us now consider that measured gravity variations are representative of areal water storage changes $\Delta S_{g}$ on the karst. Let $\overline{\Delta g}$ be the mean gravity changes related to the total water mass change. Gauss's theorem allows the following relationship:

$$
\iint_{A} \Delta g d S \approx 2 \pi G \Delta M \approx \overline{\Delta g} A
$$

where $G$ is the universal gravitational constant and $A$ is the karst recharge area. Because of its relatively flat topography and its near-horizontal sedimentary formations, the karst recharge area may be approximated by a cylinder of $\sim 5.5 \mathrm{~km}$ radius and of $\sim 200 \mathrm{~m}$ depth. Therefore, at the karst system scale, water storage changes may be approximated as forming a slab and may be expressed as

$$
\Delta S_{g}=\frac{\Delta M}{\rho_{w} A}
$$

where $\rho_{\mathrm{w}}$ is water density. Combining equations (10) and (11) yields the water storage changes:

$$
\Delta S_{g}=\frac{\overline{\Delta g}}{2 \pi G \rho_{w}}
$$

Three gravity stations located outside the karst recharge area at the southeast (Figure 1) are excluded from this computation. Combining equations (9) and (12) yields a "gravimetric" AET defined as

$$
\operatorname{AET}_{g}^{c}=P^{c}-\Delta S_{g}-\frac{Q^{c}}{A}
$$

The aforementioned quantities are given in Table 4. Interestingly, the gravimetric $\mathrm{AET}_{g}^{c}$ has always physically reasonable values, i.e., $0<$ AET $<$ PET. This may indicate that the other terms of the budget, namely, precipitation, cumulative discharge and mean gravity changes are correctly estimated. Let $\mathrm{k}$ be the ratio between $\mathrm{AET}_{g}^{c}$ and PET. In agricultural studies, this ratio between actual and potential evapotranspiration is called "crop coefficient," which is a

\begin{tabular}{|c|c|c|c|c|c|c|}
\hline & $\begin{array}{c}\text { Precipitation } \\
P^{c}(\mathrm{~mm})\end{array}$ & $\begin{array}{c}\text { Cumulative } \\
\text { Areal } \\
\text { Discharge } \\
Q^{c} / A \\
(\mathrm{~mm})\end{array}$ & $\begin{array}{l}\Delta S_{g} \\
(\mathrm{~mm})\end{array}$ & $\begin{array}{r}\mathrm{AET}_{g}^{c} \\
(\mathrm{~mm})\end{array}$ & $\begin{array}{l}\text { PET } \\
(\mathrm{mm})\end{array}$ & $k$ \\
\hline$\Delta t_{1}^{2}$ & 634 & 278 & -282 & 638 & 831 & 0.77 \\
\hline$\Delta t_{2}^{3}$ & 536 & 198 & 315 & 23 & 192 & 0.12 \\
\hline$\Delta t_{3}^{4}$ & 451 & 252 & -313 & 512 & 621 & 0.82 \\
\hline
\end{tabular}
function of the growth stage of crops [Allen et al., 1998]. Typically, the crop coefficient is close to 1 during summer

Table 4. Water Budget Contributions Between Consecutive Survey Periods ${ }^{\mathrm{a}}$

${ }^{\mathrm{a}} \mathrm{See}$ text for explanations. 
months and close to 0 during winter months, as crops are either dead or dormant. For $\Delta t_{1}^{2}$ and $\Delta t_{3}^{4}, \mathrm{AET}_{g}^{c}$ is $638 \mathrm{~mm}$ and $512 \mathrm{~mm}$, respectively, yielding $k$ values of 0.77 and 0.82 , respectively. For $\Delta t_{2}^{3}, \mathrm{AET}_{g}^{c}$ equates $23 \mathrm{~mm}$, yielding a $\mathrm{k}$ value of 0.12 .

[44] Calculated $\mathrm{k}$ values (Table 4) therefore show a similar trend as those of crop coefficients afore described. This is probably related to the fact that $\Delta t_{1}^{2}$ and $\Delta t_{3}^{4}$ include summer periods, whereas $\Delta t_{2}^{3}$ spans over a winter period (see Table 1).

[45] As a partial conclusion, we point out that in addition to rainfall and discharge, the determination of both water storage variation using gravimetry and actual evapotranspiration is mandatory if one wants to seek internal flow properties of the aquifer. As emphasized by some authors [Oudin et al., 2005], inversion of flow properties using only rainfall and discharge is flawed by the poor knowledge of the water returning to the atmosphere at different periods of the year. Because of the trade-off between internal and external water flow, winter gravity measurements could be of special interest to study flow properties of the aquifer, as evapotranspiration is limited during this period.

\subsection{Water Storage Heterogeneity Seen by Gravity Observations}

[46] Aforementioned evapotranspiration calculations are based on the hypothesis that mean gravity changes on the karst are representative of basin-scale water storage changes. This hypothesis may not be valid for the following reasons:

[47] 1 . The recharge area is not fully sampled: no gravity sites in the westernmost part of the recharge area exist (see Figure 1). The water storage changes occurring in this area remain unknown.

[48] 2. Within the sampled area, the spatial coverage of the gravity sites may not be dense enough with respect to the water storage variations horizontal wavelength. As discussed by Jacob et al. [2009], water storage changes may mostly occur within the top $\sim 60 \mathrm{~m}$ of the karst around BLAQ and BEAU site (see Figure 1). One hypothesis mentioned in this paper is that for the Durzon karst, most water storage changes occur in the epikarst at shallow depth. Because of this, gravity at each station may be mostly representative of local storage changes (within a radius $<$ $200 \mathrm{~m}$ ). If water storage change horizontal wavelength is smaller than the gravity site sampling wavelength $(\sim 1.5 \mathrm{~km})$, an aliasing effect may well exist, rendering the mean gravity change not necessarily representative of the water storage change at the aquifer scale.

[49] Another way to interpret gravity change is to consider that gravity signal at each site is first and foremost representative of local water storage. Local water storage changes $\Delta S_{g, i}$ converted from gravity changes at station $i$ using the Bouguer approximation can be expressed as:

$$
\Delta S_{g, i}=P^{c}-\mathrm{AET}_{i}^{c}-Q_{i}^{c}+\mathrm{LT}_{i}^{c}
$$

where $\operatorname{AET}_{i}^{c}$ is local cumulative actual evapotranspiration, $Q_{i}^{c}$ is local cumulative discharge due to vertical transfer and $\mathrm{LT}_{i}^{c}$ is a local cumulative lateral water transfer term (Figure $8 \mathrm{~b}$ ). We include this latter term because infiltration does not solely have a vertical component but also requires horizontal transfer toward the Durzon spring. As explained in section 5.1, rainfall is quite homogeneous at the karst recharge area scale. By contrast, local discharge, lateral transfer and AET are site-dependent, and none of which are measured. Equation (14) is therefore heavily underdetermined. Again, it appears difficult to infer internal water dynamics without the knowledge of daily actual evapotranspiration. For this reason, we first focus on the recharge period $\Delta t_{2}^{3}$ on Figure 9a. During this winter period (November to April), evapotranspiration is thought to be small compared to rainfall, which dominates the water fluxes (Table 4). Therefore, gravity changes during this period represent internal transfer processes in response to rainfall and are little influenced by evapotranspiration. To examine the local water budget terms of equation (14), we convert gravity changes at each station within the recharge area into water heights using the Bouguer approximation and represent this signal in ascending order based on $\Delta t_{2}^{3}$ measurements (Figure 9).

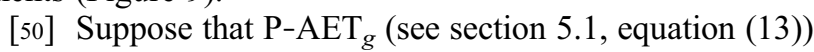
is a proxy for the net infiltration at each site; the difference between this value (cyan line on Figure 9a) and the crosses associated to $\Delta S_{g, i}$ represent the internal water transfer. Therefore, sites displaying an efficient transfer appear on the left hand side of the Figure 9a. By contrast, sites on the right hand side suggest a small net withdrawal. The highest measured water height change may be higher than rainfall. This may be interpreted in the following manner.

[51] 1. The concerned sites exhibit neither vertical discharge $Q_{i}^{c}$ nor lateral transfer term $\mathrm{LT}_{i}^{c}$, so that rainwater remains at these sites for this period.

[52] 2. Vertical discharge and lateral transfer occur but counteract each other, resulting in a static state.

[53] Conversely, low water height change stations for $\Delta t_{2}^{3}$ may also correspond to high discharge and/or lateral transfer efficiencies. The question that now arises is: are the observed trends for $\Delta t_{2}^{3}$ also observed for the gravimetric discharge periods?

[54] For $\Delta t_{1}^{2}$ and $\Delta t_{3}^{4}$, equivalent water storage changes at each site are far off from the amount of precipitation during the considered periods (Figures $9 \mathrm{~b}$ and $9 \mathrm{c}$ ). This means that for these time periods, evapotranspiration, vertical discharge and perhaps lateral transfer at each site has significantly reduced water storage fed by precipitation. The respective contributions of local AET, discharge and lateral transfer in lowering the water storage is difficult to determine. Indeed, AET may in principle range between 0 and PET and local discharge and lateral transfer are unconstrained. Therefore, the underdetermination of equation (14) is manifest and unsolvable without further information.

[55] However, stations showing the largest positive storage changes for $\Delta t_{2}^{3}$ also show the largest negative storage changes for $\Delta t_{1}^{2}$ and $\Delta t_{3}^{4}$. Conversely, stations showing little changes in recharge show little changes in discharge. An anticorrelation pattern is observed between winter and summer periods in the station gravity changes (Figure 9). It is tempting to associate the similarity between winter and summer patterns to a common mode related to hydrological behavior. Indeed, water pathways in a karst system are spatially very heterogeneous but are associated to partially reproducible hydraulic and hydromechanic behaviors in response to rainfall as shown for example by tilt recordings 

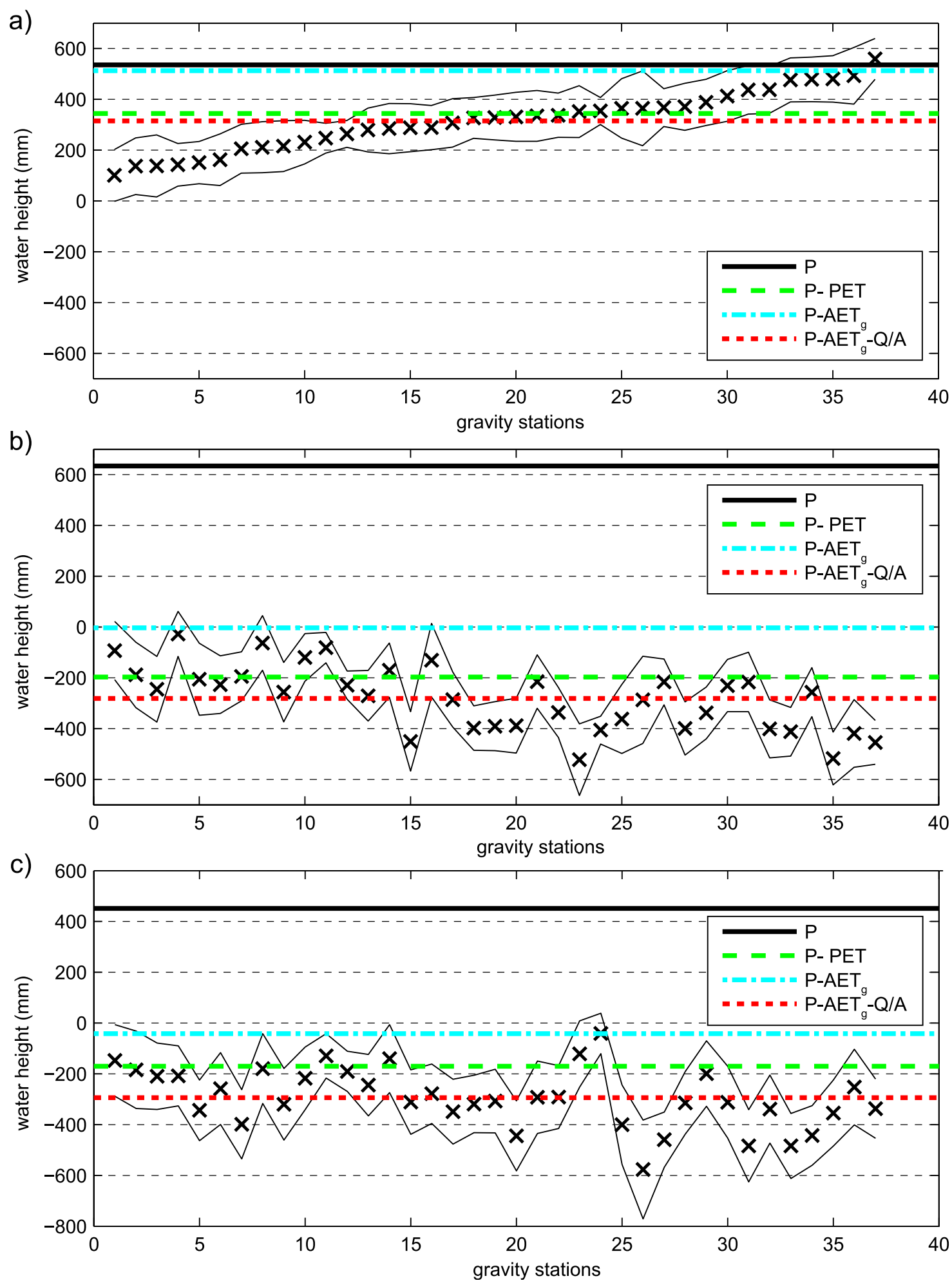

Figure 9. Measured gravity differences (crosses) and errors converted into water heights and water budget terms: (a) recharge period $\Delta t_{2}^{3}$, (b) discharge period $\Delta t_{1}^{2}$, and (c) discharge period $\Delta t_{3}^{4}$. Stations are sorted for ascending gravity values of recharge period $\Delta t_{2}^{3}$. The vertical scale is shifted for better legibility. 

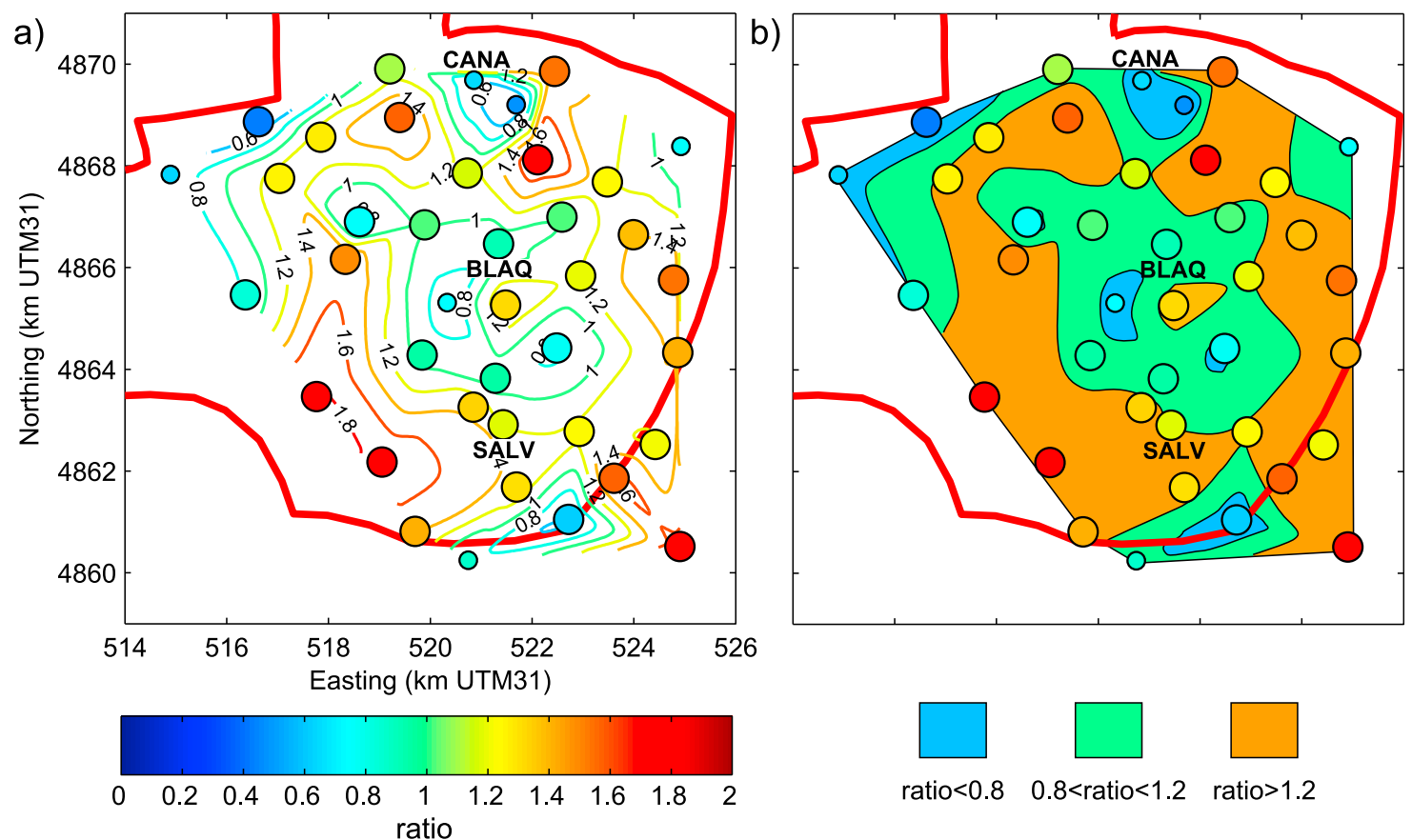

Figure 10. (a) Amplitude ratio between gravity at all sites and BLAQ AG; circle color represents ratio. Small and large circles are ratios with coefficient of determination lower and higher, respectively, than 0.7. (b) Same as Figure 10a except showing three classes of ratios.

[Braitenberg et al., 2006]. Conversely, the scatter in the summer patterns (Figures $9 \mathrm{~b}$ and $9 \mathrm{c}$ ) could be linked to the variability of actual evapotranspiration from site to site. Indeed, gravity sites are installed in highly variable soil and vegetation conditions. Soil type ranges from very thin ground layer just above massive limestone to heavily developed soils in vast depressions above karstified rock. In addition, a large variety of plants grow in the Grands Causses area from natural and cultivated crops to a moderately developed forest including oaks, beech trees and pines. The actual evapotranspiration resulting from soil/ vegetation combination is probably complex and leads us to be cautious about the interpretation of gravity measurements made during spring and summer months.

\subsection{Relationship Between Water Storage and Karst Structure}

[56] Although section 5.2 shows that it is not straightforward to discriminate the relative weight of infiltration and evapotranspiration in the gravimetric signal, contrasted high and low storage areas are likely to exist. We now discuss the spatial organization of storage change on the karst. At first glance, some similarity can be found between recharge and discharge signal in Figure 7, and this is confirmed by the inverse correlation seen on Figure 9. We attempt here to combine the spatial information on gravity change in a single plot. To do so, we compute the amplitude ratio of the gravity change at every site with respect to BLAQ gravity change. BLAQ station is chosen as a reference because it exhibits gravity variations which are closest to those of the mean gravimetric water stock defined for the entire karst system by water budget modeling [see Jacob et al., 2008,
2009]. We perform a regression analysis between the four gravity values measured at each site and those measured at BLAQ station. The mean coefficient of determination $\left(\mathrm{R}^{2}\right)$ for the linear regressions is 0.85 , and its lowest value is 0.52 , insuring that most of the gravity variations observed at the different sites are linearly related to the gravity variations at BLAQ station. Choosing SALV or CANA as the main comparison stations yields mean coefficients of determination of 0.57 and 0.51 , respectively, demonstrating poor linear relationships with these stations.

[57] The gravity amplitude ratio can be as low as 0.43 (site to the southeast of CANA) and as high as 1.83 (site to the west of SALV, see Figure 10a), with a mean value of 1.15. Areas with high-and low-gravity amplitudes with respect to BLAQ are explicitly shown on Figure 10b. Three classes of ratios are considered: ratios lower than 0.8 , ratios between 0.8 and 1.2, and ratios larger than 1.2. Ratios larger than 1.2 are found in two distinct north-south trending zones, encircling a central zone characterized by ratios between 0.8 and 1.2, comprising BLAQ station. Areas with ratios lower than 0.8 are found at the following sites: around CANA AG station; to the northwest of the recharge area and at some isolated gravity sites.

[58] The link between the gravimetric map of Figure 10 and the geologic and the karstification of the Durzon basin (Figure 1) is not obvious. Because it is well known that erosion and dissolution in a karst system initiate in areas close to the spring and progress toward distal zones when the karstic network self-organizes, it could have been expected that the observed gravity signal present some trend with respect to the spring distance. This is hardly the case. 


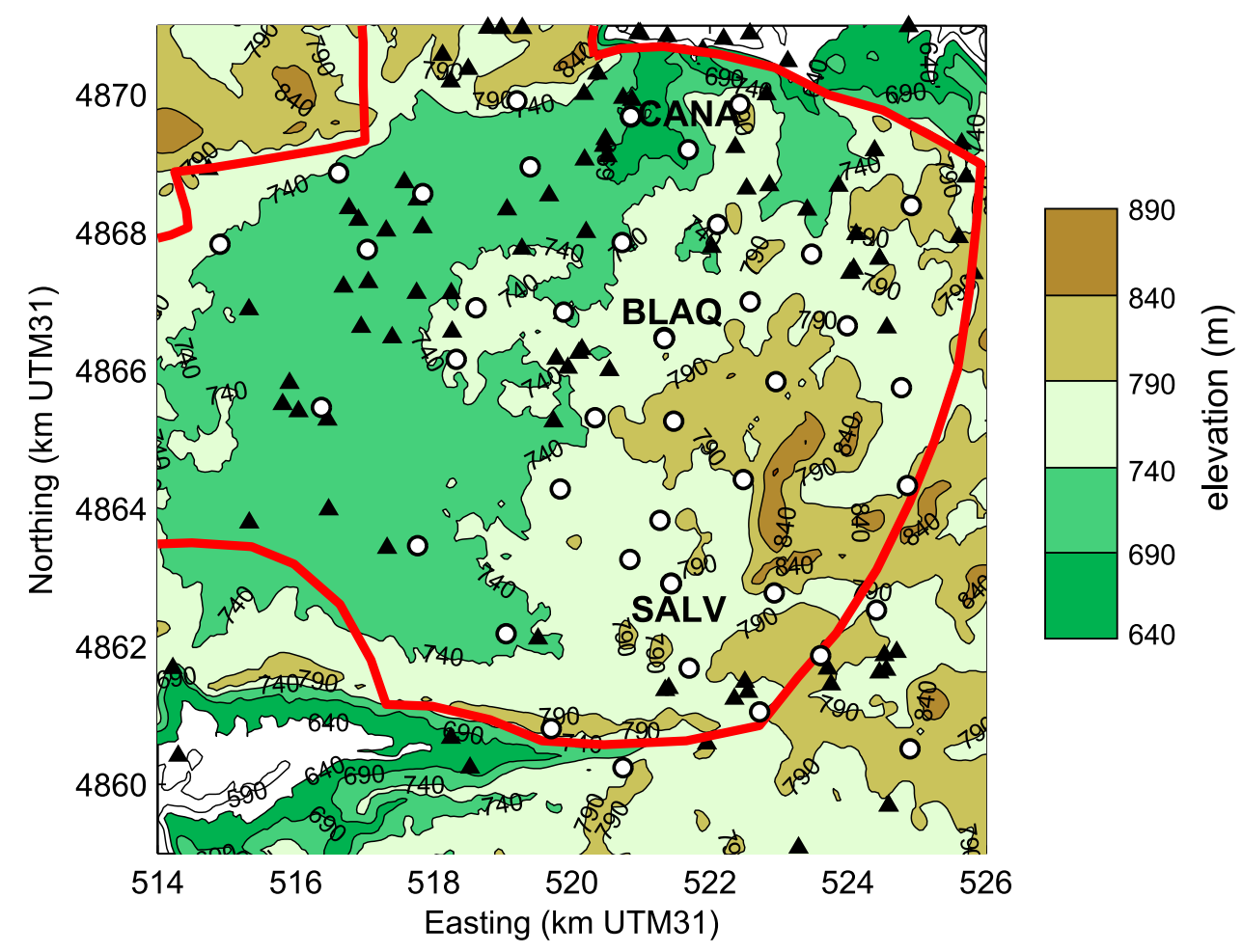

Figure 11. Topography associated to the Durzon basin. Empty circles correspond to gravity sites. Black triangles mark known cave locations.

We rather propose that some features of the gravity signal may have a geomorphologic origin:

[59] 1. In the west, large plains exist at elevation generally lower than $740 \mathrm{~m}$ (Figure 11). Embedded depressions, known as "poljes," characterize this general area. Accumulation of detritic material such as clays and dolomitic sand, known as "terra rossa" in this region, lead to thick soil covers. This accumulation mainly originates from the alteration of middle Jurassic chert limestone outcropping at the south and north of the recharge area at elevations of $\sim 800 \mathrm{~m}$. As discussed by Bruxelles [2001b], the effects of such accumulations are twofold. First, they may act as surface impervious layers, clogging karst infiltration pathways, therefore undermining efficient vertical drainage. Second, because of their high water retention capacity, underlying dolomites may be in constant contact with water, inducing their dissolution. The repartition of these detritic accumulations in space and in time may be responsible for observed poljes [Bruxelles, 2001b]. Identified high gravity variations (Figure 10b) in the southwestern area may be explained with the aforementioned geomorphologic considerations. Indeed, the two sites showing the highest ratio relative to BLAQ AG variations to the west of SALV are located in low areas with observed detritic accumulation. High-gravity amplitude areas are however not systematically in high detritic accumulation areas.

[60] 2. In contrast to the low topography of the western area, the central part of the Durzon basin between BLAQ and SALV sites correspond to elevated and hilly surfaces displaying thin soil covers due to the lack of detritic material. Because gravity variations are less pronounced here, our preferred interpretation is that the soil and the epikarst are unable to retain the water in the vadose zone during the hydrological cycle.

\subsection{Hydrological Interpretations Explaining the Observed Gravity Signal}

[61] The main water storage entities in karst systems are generally thought to be the epikarst and the phreatic zone [Mangin, 1975]. This implies that gravity changes may come from both water storage changes occurring in the epikarst and/or in the phreatic zone. However, the question of the depth of inferred water storage changes cannot be answered by surface gravity measurements alone, as the source depth cannot be constrained. This issue was addressed by Jacob et al. [2009] by the setup of a surface to depth gravity experiment. In this experiment, gravity changes between the surface and $60 \mathrm{~m}$ depth down a pothole (BEAU site on Figure 1) were compared to AG variations at the karst surface. The main result is that BLAQ AG variations are driven by water storage changes occurring in the top $60 \mathrm{~m}$ of the karst, most plausibly in the epikarst. This demonstrates the important storage capacity of this horizon. The authors then conjectured that most water storage variations occurred in the epikarst in the Durzon karst system. This generalization is only tentative and formulated with caution. Indeed, this hypothesis was formulated using three surface gravity sites, whereas in the present study, gravity changes at 40 sites can be used to test it. We now examine two hypotheses whereby (1) epikarst is the dominant storage entity and (2) both epikarst and phreatic zone contribute to storage changes.

[62] Considering epikarst as the main storage entity and therefore the main contributor to gravity changes implies the 
a)

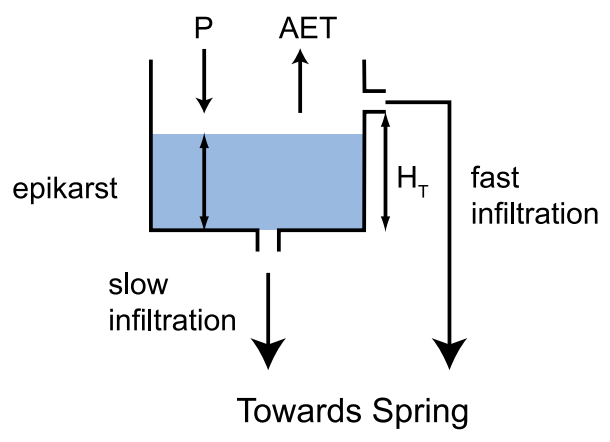

b)
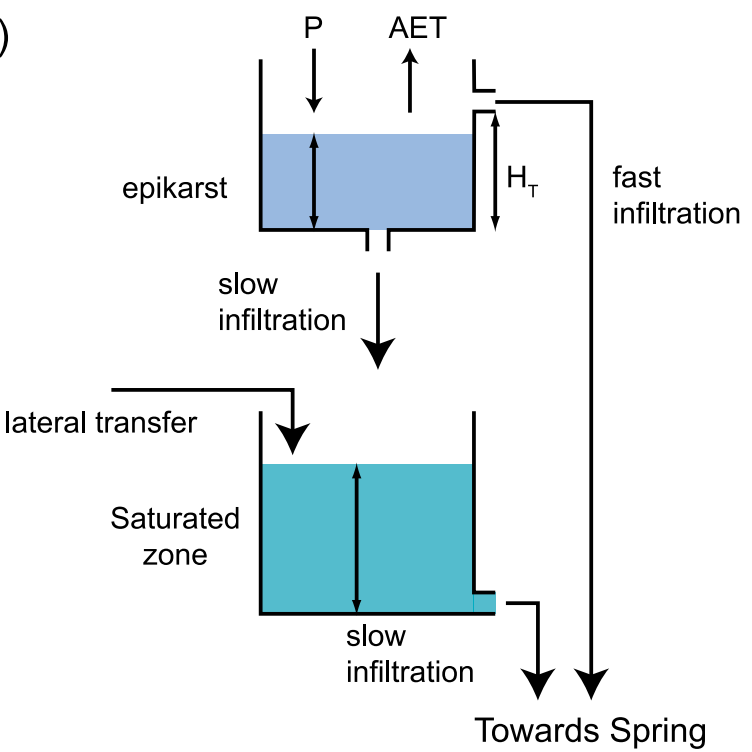

Figure 12. Theoretical transfer models (a) case 1, epikarstic storage, and (b) case 2, epikarstic and saturated zone storage.

following. At each gravity site, the epikarst may be considered as a "leaky bucket," fed by rainfall, and out of which water exits though evapotranspiration and deep infiltration. In such a reservoir model, the outflow rate is proportional to the effective water height within the medium as initially proposed by Maillet [1905]. Also, a threshold in epikarst storage value $H_{T}$ must exist above which fast infiltration occurs (Figure 12a). This threshold value has a direct influence on the amount of stored water that the epikarst may hold. Using such a model, both Durzon spring base flow and high-flow events (Figure 2c) could be accounted for.

[63] Areas of high-gravity amplitudes (Figures 9 and 10) are characterized by high storage capacities, implying high $H_{T}$ values and slow infiltration discharge rates. In this manner, the epikarst may "fill up" extensively after heavy rainfall events. Such a functioning may explain high storage changes observed for $\Delta t_{2}^{3}$. Slow infiltration and evapotranspiration may deplete epikarst water storage during warm months, accounting for the high depletion observed for $\Delta t_{1}^{2}$ and $\Delta t_{3}^{4}$ at high-gravity amplitude areas.

[64] Conversely, low-gravity amplitude zones may be characterized by a low storage epikarst. Two possible explanations may account for this.

[65] 1. Threshold value $H_{T}$ is low, meaning that a large proportion of rainwater infiltrates through fast infiltration pathways visible at the spring only during the weeks following rainfall. Therefore, this part of the inner flow does not contribute to the signal detected by our surveys.

[66] 2. Basal infiltration is efficient, so that the epikarst is drained fast regardless of $H_{T}$ values. Up to now, we assume that only the epikarst stores water and that infiltration and phreatic zones only play a transmissive function and do not store water. However, both epikarst and phreatic zones may exhibit water storage changes. Unfortunately, water level data from the phreatic zone are scarce on the karst recharge area. Among existing wells, the one situated at "Les Menudes" village is at the vicinity of a high-amplitude gravity site (Figures 1 and 10). The water table at this site is some $50 \mathrm{~m}$ below the surface, and annual amplitudes may reach a few meters (H. Jourde, personal communication, 2009). Because of the lack of other wells, it is not known if this water level corresponds to a local reservoir or not. It remains that this saturated zone may contribute to time-lapse gravity variations.

[67] For such a case, a conceptual model can be the one of Figure $12 \mathrm{~b}$ (case 2). Similar types of models have been used to simulate spring discharges of other karsts [Fleury et al., 2007a, 2007b]. Here, infiltration from the epikarst also occurs above a threshold, and this infiltration is split into infiltration feeding the fast infiltration pathways to the spring and infiltration feeding the phreatic zone reservoir. This latter reservoir may also be fed by lateral water transfer, and its emptying feeds the base flow component of the spring but also the lateral transfer component to adjacent saturated reservoirs. In this case, high-amplitude gravity changes may be due to both epikarst and saturated storage rising and falling during wet and dry periods, respectively. In opposition to case 1 , the saturated zone plays here a storage function. This kind of internal structure may correspond to annex-to-drain systems that have been described as high-head loss voids connected to drains and acting as storage entities within the phreatic zone [Bakalowicz, 2005; Mangin, 1975]. This concept may perhaps be invoked to explain a signal associated to saturated or phreatic storage.

[68] Because of the lack of continuous time series associated to our survey, both models (cases 1 and 2) can explain the observed gravity signal over the Durzon basin. Areas of high-gravity amplitude may denote both epikarst and phreatic zone storage changes (ratios over 1.2 on Figure 10). Since other studies have proposed that absolute gravity measurements at BLAQ site are representative of epikarst gravity changes alone [Jacob et al., 2009], it is possible that areas with similar gravity changes as those observed at BLAQ station (ratios between 0.8 and 1.2 on Figure 10) may 
represent areas of negligible phreatic zone storage changes with dominant storage changes occurring in the epikarst.

[69] Areas characterized by gravity amplitude ratios smaller than 0.8 are representative of zones that seasonally store little water; this stored water may be within the epikarst or the phreatic zone. This could mean that both epikarst and phreatic zone are well drained in these areas. Heavily karstified surface morphology in the low-amplitude gravity area in the spring vicinity (surrounding CANA) may attest this.

\section{Conclusion}

[70] Time-lapse microgravity surveying allowed us to monitor gravity changes at 40 sites on a karst recharge area of approximately $100 \mathrm{~km}^{2}$. The mean error on adjusted gravity values for an individual survey ranges between 2.4 and $5 \mu \mathrm{Gal}$, and consecutive survey errors range between 4 and $5.5 \mu \mathrm{Gal}$. This implies that statistically significant water storage changes of $\sim 0.25 \mathrm{~m}$ equivalent water height can be detected with our measurement protocol.

[71] Time-lapse microgravity surveys aimed at detecting water storage changes greatly benefits from AG values, inasmuch as no assumptions need to be made on the time stability of a site's gravity value, as is classically done when no absolute gravimeters are available. In fact, our gravity surveying on the studied karst system reveals that the gravity value evolves at every single site between consecutive survey periods.

[72] We use the mean gravity changes to constrain the water budget of the karst system by determining the amount of evapotranspiration water. Specifically, low evapotranspiration values are found during winter times, and large values are found between surveys during which a summer period occurs. For the winter recharge period, evapotranspiration is found to be low, so that microgravity changes are mostly representative of internal karst dynamics. Within this scope, we find that storage on the karst is heterogeneous, and that the water storage variations range from 10 to $55 \mathrm{~cm}$. We propose that a relationship exists between identified areas of high- and low-gravity amplitudes and the repartition of superficial formations. Finally, we discuss how models of water storage may explain gravity changes. Although some areas may exclusively correspond to water storage in the epikarst, zones of large gravity changes may be driven by both epikarst and saturated water storage changes.

[73] This study illustrates that field surveys with portable gravimeters, combined with absolute gravity measurements, allow a reliable measurement of water storage change over a large area. Such gravity surveys are well suited to understand complex aquifer systems such as karsts, and in particular, to quantify in a unique way recharge processes during high-rainfall and low-evapotranspiration periods. However, it must be emphasized that time-dependent water budget and inference of underground water dynamics requires precise actual evapotranspiration measurements near gravity stations.

[74] Acknowledgments. The manuscript was enhanced by the comments of M. Van Camp and an anonymous reviewer. This work was funded by the Agence Nationale à la Recherche (ANR), under the program ECCO
Hydrologie et Géodésie driven by N. Florsch. The Scintrex CG5 relative gravimeter was provided for by the Institut National des Sciences de l'Univers (INSU). We would like to express our gratitude toward the inhabitants of the Larzac region who let us use their property for absolute and relative gravity measurements. We are indebted to Michael Bonno, Marc Daignières, Frédéric Boudin, Philippe Vernant, Cédric Champollion, and Philippe Collard for their precious help on the field. We would like to thank Jacques Beilin for his help and assistance with his software MCGRAVI. Finally, we would like to acknowledge J.-P. Boy for computing the global hydrological effects.

\section{References}

Abe, M., S. Takemoto, Y. Fukuda, T. Higashi, Y. Imanishi, S. Iwano, S. Ogasawara, Y. Kobayashi, S. Dwipa, and D. S. Kusuma (2006), Hydrological effects on the superconducting gravimeter observation in Bandung, J. Geodyn., 41(1-3), 288-295, doi:10.1016/j.jog.2005.08.030.

Allen, G. A., L. S. Pereira, D. Raes, and M. Smith (1998), Crop evapotranspiration - Guidelines for computing crop water requirements, Food and Agric. Org. of the U. N., Rome.

Baedke, S. J., and N. C. Krothe (2001), Derivation of effective hydraulic parameters of a karst aquifer from discharge hydrograph analysis, Water Resour. Res., 37(1), 13-19, doi:10.1029/2000WR900247.

Bakalowicz, M. (2005), Karst groundwater: A challenge for new resources, Hydrogeol. J., 13(1), 148-160, doi:10.1007/s10040-004-0402-9.

Ballu, V., M. Diament, P. Briole, and J.-C. Ruegg (2003), 1985-1999 gravity field variations across the Asal Rift; insights on vertical movements and mass transfer, Earth Planet. Sci. Lett., 208(1-2), 41-49, doi:10.1016/ S0012-821X(03)00002-5.

Beilin, J. (2006), Apport de la gravimétrie absolue à la réalisation de la composante gravimétrique du Réseau Géodésique Français, Master thesis, Inst. Géogr. Natl., Paris.

Bonvalot, S., D. Remy, C. Deplus, M. Diament, and G. Gabalda (2008), Insights on the March 1998 eruption at Piton de la Fournaise volcano (La Reunion) from microgravity monitoring, J. Geophys. Res., 113, B05407, doi:10.1029/2007JB005084.

Bower, D. R., and N. Courtier (1998), Precipitation effects on gravity measurements at the Canadian absolute gravity site, Phys. Earth Planet. Inter., 106, 353-369, doi:10.1016/S0031-9201(97)00101-5.

Boy, J. P., and J. Hinderer (2006), Study of the seasonal gravity signal in superconducting gravimeter data, J. Geodyn., 41, 227-233, doi:10.1016/ j.jog.2005.08.035.

Braitenberg, C., G. Romeo, Q. Taccetti, and I. Nagya (2006), The verybroad-band long-base tiltmeters of Grotta Gigante (Trieste, Italy): Secular term tilting and the great Sumatra-Andaman islands earthquake of December 26, 2004, J. Geodyn., 41, 164-174, doi:10.1016/j.jog.2005.08.015.

Bruxelles, L. (2001a), Dépôts et altérites des plateaux du Larzac central: causses de l'Hospitalet et de Campestre (Aveyron, Gard, Hérault). Evolution morphogénique, conséquences géologiques et implications pour l'aménagement, Ph.D. thesis, 266 pp, Univ. de Provence, Aix-en-Provence, France.

Bruxelles, L. (2001b), Reconstitution morphologique du Causse du Larzac (Larzac central, Aveyron, France) Rôle des formations superficielles dans la morphogenèse karstique, Karstologia, 38, 25-40.

Budetta, G., and D. Carbone (1997), Potential application of the Scintrex CG-3M gravimeter for monitoring volcanic activity; results of field trials on Mt. Etna, Sicily, J. Volcanol. Geotherm. Res., 76(3-4), 199-214, doi:10.1016/S0377-0273(96)00080-7.

Crossley, D., J. Hinderer, and J. P. Boy (2005), Time variation of the European gravity field from superconducting gravimeters, Geophys. J. Int., 161, 257-264, doi:10.1111/j.1365-246X.2005.02586.x.

Debeglia, N., and F. Dupont (2002), Some critical factors for engineering and environmental microgravity investigations, J. Appl. Geophys., 50(4), 435-454, doi:10.1016/S0926-9851(02)00194-5.

Dewandel, B., P. Lachassagne, M. Bakalowicz, P. Weng, and A. Al-Malki (2003), Evaluation of aquifer thickness by analysing recession hydrographs. Application to the Oman ophiolite hard-rock aquifer, J. Hydrol., 274(1-4), 248-269, doi:10.1016/S0022-1694(02)00418-3.

Ergintav, S., U. Dogan, C. Gerstenecker, R. Cakmak, A. Belgen, H. Demirel, C. Aydin, and R. Reilinger (2007), A snapshot (2003-2005) of the 3D postseismic deformation for the $1999, \mathrm{Mw}=7.4$ Izmit earthquake in the Marmara Region, Turkey, by first results of joint gravity and GPS monitoring, J. Geodyn., 44, 1-18, doi:10.1016/j.jog.2006.12.005.

Ferguson, J. F., T. Chen, J. L. Brady, L. V. Aiken, and J. Seibert (2007), The 4D microgravity method for waterflood surveillance: II-Gravity measurements for the Prudhoe Bay reservoir, Alaska, Geophysics, 72(2), I33-I43, doi:10.1190/1.2435473.

Ferguson, J. F., F. Klopping, T. Chen, J. Seibert, J. Hare, and J. L. Brady (2008), The 4D microgravity method for waterflood surveillance: Part 3- 
4D absolute microgravity surveys at Prudhoe Bay, Alaska, Geophysics, 73(6), WA163-WA171, doi:10.1190/1.2992510.

Fleury, P., M. Bakalowicz, and M. Becker (2007a), Characterising a karst system with a submarine spring: The example of La Mortola (Italy), C. $R$. Acad. Sci. Geosci., 339(6), 407-417, doi:10.1016/j.crte.2007.04.004

Fleury, P., V. Plagnes, and M. Bakalowicz (2007b), Modelling of the functioning of karst aquifers with a reservoir model: Application to Fontaine de Vaucluse (south of France), J. Hydrol., 345(1-2), 38-49, doi:10.1016/ j.jhydrol.2007.07.014.

Flury, J., T. Peters, L. Schmeer, L. Timmen, H. Wilmes, and R. Falk (2006), Precision gravimetry in the new Zugspitze gravity meter calibration system, paper presented at 1st International Symposium of the International Gravity Field Service "Gravity Field of the Earth," Istanbul, Turkey.

Francis, O., M. Van Camp, T. van Dam, R. Warnant, and M. Hendrickx (2004), Indication of the uplift of the Ardenne in long-term gravity variations in Membach, Belgium, Geophys. J. Int., 158, 346-352, doi:10.1111/j.1365-246X.2004.02310.x.

Furuya, M., S. Okubo, W. Sun, Y. Tanaka, J. Oikawa, H. Watanabe, and T. Maekawa (2003), Spatiotemporal gravity changes at Miyakejima Volcano, Japan: Caldera collapse, explosive eruptions and magma movement, J. Geophys. Res., 108(B4), 2219, doi:10.1029/2002JB001989.

Gehman, C. L., D. L. Harry, W. E. Sanford, J. D. Stednick, and N. A. Beckman (2009), Estimating specific yield and storage change in an unconfined aquifer using temporal gravity surveys, Water Resour. Res. 45, W00D21, doi:10.1029/2007WR006096.

Goodkind, J. M. (1999), The superconducting gravimeter, Rev. Sci. Instrum. 70(11), 4131-4152, doi:10.1063/1.1150092

Harnisch, G., and M. Harnisch (2006), Hydrological influences in long gravimetric data series, J. Geodyn., 41, 276-287, doi:10.1016/j. jog.2005.08.018

Hinderer, J., and D. Crossley (2000), Time variations in gravity and inferences of the Earth's structure and dynamics, Surv. Geophys., 21, 1-45, doi:10.1023/A:1006782528443

Hwang, C., C. G. Wang, and L.-H. Lee (2002), Adjustment of relative gravity measurements using weighted and datum-free constraints, Comput. Geosci., 28(9), 1005-1015, doi:10.1016/S0098-3004(02)00005-5.

Imanishi, Y., K. Kokubo, and H. Tatehata (2006), Effect of underground water on gravity observation at Matsushiro, Japan, J. Geodyn., 41, 221-226, doi:10.1016/j.jog.2005.08.031.

Jacob, T., R. Bayer, J. Chery, H. Jourde, N. Le Moigne, J. P. Boy, J. Hinderer, B. Luck, and P. Brunet (2008), Absolute gravity monitoring of water storage variation in a karst aquifer on the Larzac plateau (southern France), J. Hydrol., 359(1-2), 105-117, doi:110.1016/j.jhydrol. 2008.1006.1020

Jacob, T., J. Chery, R. Bayer, N. Le Moigne, J. P. Boy, P. Vernant, and F. Boudin (2009), Time-lapse surface to depth gravity measurements on a karst system reveal the dominant role of the epikarst as a water storage entity, Geophys. J. Int., 177, 347-360, doi:10.1111/j.1365-246X. 2009.04118.x

Jousset, P., M. VanRuymbeke, S. Bonvalot, and M. Diament (1995), Performance of two Scintrex CG3M instruments at the fourth International Comparison of Absolute Gravimeters, Metrologia, 32(3), 231-244, doi:10.1088/0026-1394/32/3/012.

Jousset, P., S. Dwipa, F. Beauducel, T. Duquesnoy, and M. Diament (2000), Temporal gravity at Merapi during the 1993-1995 crisis; an insight into the dynamical behaviour of volcanoes, J. Volcanol. Geotherm. Res., 100(1-4), 289-320, doi:10.1016/S0377-0273(00)00141-4.

Kovacs, A., P. Perrochet, L. Kiraly, and P. Y. Jeannin (2005), A quantitative method for the characterisation of karst aquifers based on spring hydrograph analysis, J. Hydrol., 303(1-4), 152-164, doi:10.1016/j. jhydrol.2004.08.023.

Kroner, C., and T. Jahr (2006), Hydrological experiments around the superconducting gravimeter at Moxa Observatory, J. Geodyn., 41, 268-275, doi:10.1016/j.jog.2005.08.012.

Lambert, A., and C. Beaumont (1977), Nano variations in gravity due to seasonal groundwater movements; implications for the gravitational detection of tectonic movements, J. Geophys. Res., 82, 297-306, doi:10.1029/JB082i002p00297.

Lambert, A., N. Courtier, and G. S. Sasagawa (2001), New constraints on Laurentide postglacial rebound from absolute gravity measurements, Geophys. Res. Lett., 28, 2109-2112, doi:10.1029/2000GL012611.

Larson, K. M., and T. Van Dam (2000), Measuring postglacial rebound with GPS and absolute gravity, Geophys. Res. Lett., 27(23), 39253928, doi:10.1029/2000GL011946.

Liard, J., and C. Gagnon (2002), The new A-10 absolute gravimeter at the 2001 International comparison of absolute gravimeters, Metrologia, 39(5), 477-483, doi:10.1088/0026-1394/39/5/8
Lyard, F., F. Lefevre, T. Letellier, and O. Francis (2006), Modelling the global ocean tides: Modern insights from FES2004, Ocean Dyn. 56(5-6), 394-415, doi:10.1007/s10236-006-0086-x.

Maillet, E. (1905), Essais d'Hydraulique Souterraine et Fluviale, 218 pp., Hermann, Paris.

Mäkinen, J., and S. Tattari (1988), Soil moisture and groundwater: Two sources of gravity variations, Bull. Inf. Marees Terr., 63, 103-110.

Mangin, A. (1975), Contribution à l'étude hydrodynamique des aquifères karstiques, Ph.D. thesis, 124 pp, Univ. de Bourgogne, Dijon.

Merlet, S., A. Kopaev, M. Diament, G. Geneves, A. Landragin, and F. Pereira Dos Santos (2008), Micro-gravity investigations for the LNE watt balance project, Metrologia, 45, 265-274, doi:10.1088/ 0026-1394/45/3/002.

Meurers, B., M. Van Camp, and T. Petermans (2007), Correcting superconducting gravity time-series using rainfall modelling at the Vienna and Membach stations and application to Earth tide analysis, J. Geod, 81(11), 703-712, doi:10.1007/s00190-007-0137-1.

Monteith, J. L. (1965), Evaporation and the environment, in The State and Movement of Water in Living Organisms, XIXth Symposium, pp. 205-234, Academic, New York.

Naujoks, M., A. Weise, C. Kroner, and T. Jahr (2008), Detection of small hydrological variations in gravity by repeated observations with relative gravimeters, J. Geod., 82(9), 543-553, doi:10.1007/s00190-007-0202-9.

Niebauer, T. M. (1989), The effective measurement height of free-fall absolute gravimeters, Metrologia, 26, 115-118, doi:10.1088/00261394/26/2/005.

Niebauer, T. M., G. S. Sasagawa, J. E. Faller, R. Hilt, and F. Klopping (1995), A new generation of absolute gravimeters, Metrologia, 32, 159-180, doi:10.1088/0026-1394/32/3/004

Oudin, L., C. Michel, and F. Anctil (2005), Which potential evapotranspiration input for a lumped rainfall-runoff model? Part 1 - Can rainfall-runoff models effectively handle detailed potential evapotranspiration inputs? J. Hydrol., 303(1-4), 275-289, doi:10.1016/j.jhydrol.2004.08.025.

Penman, H. L. (1948), Natural evaporation from open water, bare soil and grass, Proc. R. Soc. London, 193, 120-145, doi:10.1098/rspa.1948.0037. Plagnes, V. (1997), Structure et fonctionnement des aquifères karstiques. Caractérisation par la chimie des eaux, Ph.D. thesis, 372 pp., Univ. of Montpellier II, Montpellier, France.

Pool, D. R. (2008), The utility of gravity and water-level monitoring at alluvial aquifer wells in southern Arizona, Geophysics, 73(6), WA49-WA59, doi:10.1190/1.2980395.

Pool, D. R., and J. H. Eychaner (1995), Measurements of Aquifer-Storage Change and Specific Yield Using Gravity Surveys, Ground Water, 33(3), 425-432, doi:10.1111/j.1745-6584.1995.tb00299.x.

Rebscher, D., M. Westerhaus, W. Welle, and I. Nandaka (2000), Monitoring ground deformation at the decade volcano Gunung Merapi, Indonesia, Phys. Chem. Earth Part A, 25(9-11), 755-757, doi:10.1016/S1464 1895(00)00117-4

Ricard, J., and M. Bakalowicz (1996), Connaissance, aménagement et protection des ressources en eau du Larzac septentrional, Aveyron (France), 94 pp., Bur. de Rech. Géol. et Min., Orléans, France.

Schmerge, D. L. (2003), The application of microgravimetry to aquiferstorage change monitoring, Cah. Cent. Eur. Geodyn. Seismol., 22, $161-165$.

Scintrex Limited (2006), CG5 Scintrex autograv system Operation Manual, Scintrex Limited, Concord, Ont., Canada.

Tamura, Y. (1987), A harmonic development of the tide generating potential, Bull. Inf. Marees Terr., 99, 6813-6855.

Timmen, L. (2003), Precise definition of the effective measurement height of free-fall absolute gravimeters, Metrologia, 40, 62, doi:10.1088/00261394/40/2/310.

Van Camp, M., S. D. P. Williams, and O. Francis (2005), Uncertainty of absolute gravity measurements, J. Geophys. Res., 110, B05406, doi:10.1029/2004JB003497.

Van Camp, M., P. Meus, Y. Quinif, O. Kaufman, M. Van Ruymbeke, M. Vandiepenbeeck, and T. Camelbeek (2006a), Karst aquifer investigation using absolute gravity, Eos Trans. AGU, 87(30), 298, doi:10.1029/ 2006EO300005

Van Camp, M., M. Vanclooster, O. Crommen, T. Petermans, K. Verbeeck, B. Meurers, T. van Dam, and A. Dassargues (2006b), Hydrogeological investigations at the Membach station, Belgium, and application to correct long periodic gravity variations, J. Geophys. Res., 111, B10403, doi:10.1029/2006JB004405.

Viterbo, P., and A. C. M. Beljaars (1995), An improved land surface parameterization scheme in the ECMWF model and its validation, J. Clim., 827162748 doi:10.1175/1520-0442(1995)008<2716:AILSPS $>$ $2.0 . \mathrm{CO} 2$ 
Wahr, J., S. Swenson, V. Zlotnicki, and I. Velicogna (2004), Time-variable gravity from GRACE: First results, Geophys. Res. Lett., 31, L11501, doi:10.1029/2004GL019779.

Wenzel, H.-G. (1996), The Nanogal software: Earth tide data processing package ETERNA 3.30, Bull. Inf. Marees Terr., 124, 9425-9439.

Williams, P. W. (1983), The role of the subcutaneous zone in karst hydrology, J. Hydrol., 61, 45-67, doi:10.1016/0022-1694(83)90234-2.

Williams, P. W. (2008), The role of the epikarst in karst and cave hydrogeology: A review, Int. J. Speleol., 37(1), 1-10.
Zumberge, M. A. (1981), A portable apparatus for absolute measurements of the Earth's gravity, Univ. of Colo., Boulder.

R. Bayer, J. Chery, and N. Le Moigne, Géosciences Montpellier, UMR 5243, CNRS, Université Montpellier II, 4 place Eugene Battaillon, F-34095 Montpellier CEDEX 05, France.

T. Jacob, CIRES, University of Colorado at Boulder, 216 UCB, Boulder, CO 80309-0216, USA. (Thomas.Jacob@Colorado.edu) 